\title{
Natural toxic impact and thyroid signaling interplay orchestrates riverine adaptive divergence of Dolly Varden.
}

\section{Evgeny V. Esin}

A.N. Severtsov Institute of ecology and evolution, RAS

\section{Grigorii N. Markevich}

Krontsky Nature Biosphere Reserve

\section{Nikolay O. Melnik}

A.N. Severtsov Institute of ecology and evolution, RAS

\section{Daria V. Kapitanova}

A.N. Severtsov Institute of ecology and evolution, RAS

Fedor N. Shkil ( $\sim$ fedorshkil@gmail.com )

A.N. Severtsov Institute of ecology and evolution, RAS https://orcid.org/0000-0002-5637-8278

\section{Research article}

Keywords: adaptive radiation, toxic impact, thyroid hormones, salmonids, Kamchatka River

Posted Date: March 3rd, 2020

DOl: https://doi.org/10.21203/rs.3.rs-15718/v1

License: (c) (1) This work is licensed under a Creative Commons Attribution 4.0 International License. Read Full License 


\section{Abstract}

\section{Background}

Adaptive radiation in fishes has been actively investigated over the last decades. Along with numerous well-studied cases of lotic radiation, some examples of riverine sympatric divergence have been recently discovered. In contrast to the lakes, the riverine conditions do not provide evident stability in the ecological gradients. Consequently, external factors triggering the radiation, as well as developmental mechanisms underpinning it, remain unclear. Herein, we present the comprehensive study of external and internal drivers of the riverine adaptive divergence of the salmonid fish Salvelinus malma. In the Kamchatka River, this species splits in the reproductively isolated morphs that drastically differ in ecology and morphology: the benthivorous Dolly Varden (DV) and the piscivorous Stone charr (SC). To understand why and how these morphs originated, we performed a series of field and experimental work, including common-garden rearing, comparative ontogenetic, physiological and endocrinological analyses, hormonal "engineering" of phenotypes.

Results

We revealed that the type of spawning ground acts as the main external factor driving the radiation of S. malma . In contrast to DV spawning in the leaf krummholz zone, SC reproduces in the zone of coniferous forest, which litter has a toxic impact on developing fishes. SC enhances resistance to the toxicants via metabolism acceleration provided by the elevated thyroid hormone content. These physiological changes lead to the multiple heterochronies resulting in a specific morphology and SC's expansion into a piscivorous niche.

\section{Conclusions}

S. malma represents a notable example of how the thyroid axis contributes to the generation of diverse phenotypic outcomes underlying the riverine sympatric divergence. Our findings, along with the paleoecology data concerning spruce forest distribution during the Pleistocene, provide an opportunity to reconstruct a scenario of S. malma divergence. Taken together, obtained results with the data of the role of thyroid hormones in the ontogeny and diversification of fishes contribute a resource to consider the thyroid axis as a prime director orchestrating the phenotypic plasticity promoting evolutionary diversification under the changing environmental conditions.

\section{Background}

Sympatric speciation commonly arising from competing for resources is widely distributed throughout various fish taxa (Robinson \& Wilson, 1994; Bolnick \& Fitzpatrick, 2007; Via, 2009; Nosil, 2012). The most spectacular examples of sympatric divergence are known for lacustrine fishes thus making them a viable model to probe for in various evolutionary endeavours (Smith \& Skulason, 1996; Fitzpatrick et al., 2008). The assemblages of monophyletic species/morphs differing in their ecology and morphology, i.e. 'flocks', 
are present in hundreds of lakes (Johnson \& Johnson, 2001; Robinson \& Parsons, 2002; Elmer et al., 2010; Salzburger, 2018). Stable ecological cycles are believed to be essential to increase the effectiveness of resource sharing from generation to generation and for adaptive radiation and speciation in the lakes (Schluter, 1996; Carroll et al., 2007; McPhee et al., 2012). Over the last few decades, many genetic and developmental mechanisms underlying lacustrine adaptive radiation have been revealed. Notably, the early-life heterochronies induced by the alteration of developmental tuning are among the main sources of novel phenotypes in lakes (Parsons et al., 2014; Powder et al., 2015; Kratochwil et al., 2015; Le Pabic et al., 2016; Esin et al., 2018a; Kapralova et al., 2015; Shkil et al., 2015).

In contrast to lacustrine environment, the riverine one does not display evident stability in the ecological gradients. Nevertheless, a few riverine fish flocks have been discovered. The most well-known examples are the sympatric assemblages of barbs in the rivers of the Ethiopian highlands (Golubtsov et al., 2012; Levin et al., 2019), cichlids from the Kongo, the Middle Paraná basin, the Amazon and the Orinoco rivers (Pialek et al., 2011; Pialek et al., 2019; Schwarzer et al., 2011), and mormyrids from the Kongo and the Ogooue rivers (Sullivan et al., 2002; Feulner et al., 2008; Arnegard et al., 2010). Compared to the lacustrine flocks, these cases have been dramatically less studied. Research largely focused on morphology, food preferences and phylogenetic relationships among the sympatric morphs, but the ontogenetic mechanisms as well as the environmental drivers of the adaptive radiation were poorly defined and still remain unclear.

In order to ascertain external and internal factors driving riverine adaptive radiation, we studied the 'flock' of charrs (Salmonidae) dwelling in the Kamchatka River. This basin is one of the most ancient and the largest water net of the North Pacific, which was not glaciated during the late Pleistocene (Chereshnev, 1998; Elias \& Brigham-Grette, 2013; Barr \& Solomina, 2015). In the absence of glaciers, the Kamchatka River acted as a refugium providing for a diversity burst in the lineage of the charr Salvelinus malma (Brunner et al., 2001; Oleinik et al., 2015). Along with the partially anadromous Dolly Varden (DV) there are several scarcely investigated sympatric non-anadromous morphs: i) the benthivorous morph inhabiting the upper tributaries; ii) the light-colored piscivorous morph in the lower course; and iii) the marble-colored piscivorous morph in the middle course of the river (Savvaitova, 1970 and 1989; Savvaitova \& Maksimov, 1970; Pavlov \& Savvaitova, 1991; Bugaev et al., 2007; Salmenkova et al., 2009).

The morphological and ecological peculiarities of the latter, the so-called 'stone charr' (SC), were described in detail (Savvaitova \& Maksimov, 1970; Pavlov \& Savvaitova, 1991; Melnik et al., 2020). As it was established, SC is defined by the traits typical of a piscivorous fish: a big head, elongated jaws, the presence of basibranchial teeth and barbs on gill rakers, caudally shifted fins, and reduced pyloric caeca number. It also has a specific pigment pattern and demonstrates an accelerated growth rate as contrasted to DV. The studies of microsatellite polymorphism, mtDNA and nuclear DNA marker variability demonstrated that $\mathrm{SC}$ is an isolated morph, which diverged from DV in the late Pleistocene - the early Holocene (Melnik et al., 2020). 
The spawning sites of DV and SC are spatially segregated. The former migrates to spawn upstream to the leaf krummholz zone, while the latter breeds in the lower sections located in the coniferous forest. These sites do not display substantial discrepancies in the annual temperature regimes and water velocity, but drastically differ in the composition of bottom substrate and water chemistry. DV spawns on the pure pebble substrate, whereas SC reproduces on the substrate covered with a layer of conifer needles (Melnik et al., 2020). The conifer litter displays lower decomposition rate than the leaf one (Graca, 2001; Laitung et al., 2002; Ormerod et al., 2004). It also deoxygenates, acidifies the water, and continually supplies the environment by potentially toxic water-soluble and suspended compounds (Tremolieres, 1988). In the excess concentration, the flavonoids and terpenoids from the conifer litter express prooxidant activity inducing oxidative stress in vertebrates (Pietta et al., 1998; Eghbaliferiz \& Iranshahi, 2016). The pollutant concentration is significantly higher at SC spawning sites than at DV ones and has been regarded as the only crucial discrepancy between them (Melnik et al., 2020). This finding suggests that the toxic impact is an environmental trigger of the SC divergence. Considering that fishes dwelling the polluted environment commonly enhance their resistance to the toxicants via increasing their metabolic rate (Heath, 1995; Kooijman et al., 2009; Esin et al., 2018b), the same adaptation was put forward for SC.

Multiple phenotypic novelties arising in rather a short evolutionary period coupled with a low level of genetic changes indicate the impact of an internal factor influencing numerous critical decisions over the course of SC life history. Among others, thyroid hormone (TH) level seems to be the most likely candidate due to their pleiotropic effect on the development and phenotype of fishes. TH influence the metabolic rate, the rate and timing of various ontogenetic events including skeletal and pigment patterning, affect the morphology, behavior and reproduction (Janz, 2000; Blanton \& Specker, 2007; Shkil et al., 2012; McMenamin et al., 2014; Campinho, 2019; Eales, 2019; Keer et al., 2019; Saunders et al., 2019). Given the plasticity of thyroid axis in response to the environmental changes, many authors regard the alterations of thyroid signaling activity as one of the main mechanisms underpinning the adaptive radiation in teleosts (Kitano et al., 2010; Shkil et al., 2015; Bolotovskiy et al., 2018; Galindo et al., 2019; Prazdnikov \& Shkil, 2019). Following them, we propose thyroid signaling as an internal factor driving the occurrence of SC phenotypic novelties in response to the toxic environment produced by coniferous litter.

To test this hypothesis we performed a series of field and laboratory works: (1) assessed the resistance of both morphs to the conifer litter decomposition products ; (2) compared the metabolic and developmental rates, somatic growth, temporal characteristics of skull ossification, and ontogenetic dynamics of TH level in DV and SC; and (3) examined the contribution of TH in the occurrence of phenotypic novelties and resistance to the conifer litter decomposition products.

\section{Results}

Normal development 
The diameter of SC and DV eggs was similar: $0.58 \pm 0.13 \mathrm{~cm}$ and $0.50 \pm 0.15 \mathrm{~cm}$, respectively (t-test df = $98 p=0.889)$. In SC group, the hatching occurred at 335370 (50\% achievement $~ 350)$ day*degree post fertilization, whereas in DV group it occurred later, at 360400 ( 380) day*degree post fertilization. The size and weight characteristics of the newly hatched SC and DV were commensurable, $F L=1.61 .9 \mathrm{~cm}$ and $W=6580 \mathrm{mg}$. The transition to larva stage proceeded in SC at 105165 (50\% 150) day*degree post hatching (= ddph), in DV at $130190(\sim 170)$ ddph. The onset of the fry stage occurred in SC at 450530 ( 510) ddph, and 490570 ( 540) ddph in DV (Fig. 1, upper inset). For the description of the postnatal developmental stages see Methods section (also Supplementary Fig. S1).

The significant differences in FL and W between the experimental SC and DV were found at 500 ddph (Fig. 1a and b). These discrepancies increased 215 dd later at the end of the experiment, and FL / W of SC fry were larger about $15 \%$ / 40\%, respectively, than those characteristics of DV fry. In nature the differences in FL and W were found as well. The wild SC parrs ( $850 \mathrm{ddph})$ were significantly larger than the same-aged DV parrs (Table S2).

The total whole-body triiodothyronine $\left(T_{3}\right)$ content was similar in the newly hatched SC and DV. Then, prior to the onset of external feeding, both groups displayed a synchronous drop of the hormonal level. In $\mathrm{SC}$, the decrease was more pronounced $\left(\mathrm{H}-\mathrm{W}\right.$ test $\mathrm{H}_{5 ; 131}=21.27 \mathrm{p}=0.0160$ for SC and $\mathrm{H}_{5 ; 186}=18.32 \mathrm{p}=$ 0.0242 for DV). As the result, at $160 \mathrm{ddph} S C$ and DV prelarvae significantly differed in $\mathrm{T}_{3}$ content (Fig. 2). In further development, until the transition to the fry stage, SC and DV demonstrated similar positive dynamics of $T_{3}$. At the fry stage, the hormonal level within the groups did not display any serious fluctuations, but differences between the groups increased. At the end of the experiment, SC fry had significantly higher level of $T_{3}$. In nature SC parrs demonstrated the significantly higher values of $T_{3}$ content relative to $D V$ parrs. The $T_{3}$ content values in both $S C$ and $D V$ wild parrs were 1.31.4 times higher than those detected for the experimental fry (U test $d f=39 p=0.0052$ for SC and $d f=59 p=0.0094$ for DV) (Fig. 2).

The ontogenetic dynamics of the whole-body thyroxin $\left(T_{4}\right)$ content was similar in the experimental SC and DV. Both morphs displayed a gradual increase of $\mathrm{T}_{4}$ level from the hatching to the fry stage $\left(\mathrm{H}_{3 ; 17}=\right.$ $6.58 \mathrm{p}=0.0310$ for $\mathrm{SC}$ and $\mathrm{H}_{4 ; 20}=8.11 \mathrm{p}=0.0397$ for DV). Nevertheless, we found a significantly lower hormone level in SC larvae and fry compared with the same-aged DV (Fig. S2).

We did not reveal any significant fluctuations of the biochemical parameters within the groups of experimental fry ( $\mathrm{H}$ tests $\mathrm{p}>0.05$ for all parameters). However, the stable differences between the artificially reared SC and DV fry, as well as between the wild SC and DV parrs were noted (Fig. 3). In the wild and experimental DV, the blood glucose level was significantly higher than in the wild and experimental SC. The phospholipid content was significantly higher in the wild DV than in the wild SC. The same but insignificant differences in the phospholipid content were detected for the experimental DV and SC. In contrast, the tissue antioxidant activity in the experimental DV was significantly lower than in SC. 
We failed to find distinguishable discrepancies in the head and body shape between the experimental SC and DV at the early life stages: in prelarvae Procrustes ANOVA $F_{1 ; 49}=1.26 p=0.1756, S_{\text {ind } / \text { res }}=$ $0.023 / 0.068$; in larvae $F_{1 ; 49}=1.13 p=0.2005, S_{\text {ind/res }}=0.030 / 0.077$, and in late larvae $F_{1 ; 44}=3.66 p=$ $0.06122, \mathrm{SS}_{\text {ind/res }}=0.019 / 0.054$. The first significant differences occurred at the fry stage, after $500 \mathrm{ddph}$ $\left(F_{1 ; 49}=5.24 p=0.0322, S_{\text {ind } / \text { res }}=0.024 / 0.080\right)$. At the end of the experiment these discrepancies became more pronounced $\left(F_{1 ; 49}=12.08 p=0.0010, S_{\text {ind } / \text { res }}=0.029 / 0.071\right)$.

The plot of principal component scores depicted the ontogenetic channels of SC and DV, and the timing once morphological differences appeared (Fig. 4a). At the early stages (prelarva, larva and late larva) DV and SC had partially overlapping channels. During the transition to the fry stage, the channels of both morphs changed the direction and, at the fry stage (>650 ddph), became separate. According to the landmark loadings on PC2 (Table S1), the most expressed differences between SC and DV fry occurred in the eye diameter, maxilla length, head height, and ventral fins position. These morphological discrepancies were reflected in the 'consensus' body shapes stretching along the canonical root (Fig. 4b and Table S1), which clearly demonstrated the head enlargement and the caudal shift of the fins in SC fry relative to DV fry. Similar morphometric differences were revealed for the wild parrs of SC and DV (Fig. 4c). The additional data concerning the main differences in the head proportions and fin position in experimental fry and wild parrs are present in Table S2.

SC and DV differed in the ossification rate of skull bones. The MANCOVA showed that, despite the strong effect of age ( $p \leq 0.0321)$, a 'group' predictor was significant in determining the ossification rate of supraethmoid, frontal bone, maxilla, vomer and preopercle (Table). Two 'modules' of cranial ossifications - neurocranium and teeth-armed bones - displayed significant differences in the developmental rates between SC and DV. Thus, the initial advancement in ossification of the neurocranium in SC prelarvae was replaced by the retardation during the subsequent developmental stages (Fig. 5a). As the result, DV demonstrated a significantly more ossified neurocranium starting from the larva stage. In contrast, the teeth-armed bones displayed an accelerated ossification in SC from the early stages (Fig. 5b). The ossification rate of preopercle resembled the ossification pattern of the neurocranium bones being advanced in DV. The intraoral tongue-bite apparatus did not demonstrate a significant difference in ossification rate. We discovered a minor advancement in the ossification of these bones in the SC late fry (Fig. 5c). The comparative analysis of postcranial skeleton revealed differences in counts of ossified vertebrae: $61.3 \pm 0.4$ (from 59 to 63 ) in SC and $62.4 \pm 0.3$ (6064) in DV. Other structures did not display any discrepancies.

Table. Results of MANCOVA for 13 skeletal elements developmental rate in experimental SC and DV 


\begin{tabular}{|llllllll|}
\hline Skeletal element & \multicolumn{2}{l}{ Group (SC vs DV) } & \multicolumn{2}{l}{ Age (ddph) } & \multicolumn{3}{l|}{ Group $*$ age } \\
\cline { 2 - 8 } & $\mathbf{F}_{12 ; 170}$ & $\mathbf{p}$ & $\mathbf{F}_{96 ; 1155}$ & $\mathbf{p}$ & $\mathbf{F}_{12 ; 170}$ & $\mathbf{p}$ \\
\hline Supraethmoid & 4.51 & 0.0442 & 9.82 & 0.0001 & 14.322 & $<0.0001$ \\
\hline Frontal bone & 8.92 & 0.0007 & 8.88 & 0.0001 & 20.48 & $<0.0001$ \\
\hline Orbital series & 1.98 & 0.4740 & 17.13 & $<0.0001$ & 11.14 & $<0.0001$ \\
\hline Parasphenoid & 1.41 & 0.7191 & 13.84 & $<0.0001$ & 9.52 & 0.0001 \\
\hline Premaxilla & 4.03 & 0.0622 & 16.6 & $<0.0001$ & 21.64 & $<0.0001$ \\
\hline Maxilla & 4.53 & 0.0452 & 7.63 & 0.0002 & 6.63 & 0.0003 \\
\hline Dentary & 2.71 & 0.1551 & 14.62 & $<0.0001$ & 10.62 & 0.0001 \\
\hline Vomer & 7.94 & 0.0014 & 11.38 & $<0.0001$ & 4.62 & $<0.0001$ \\
\hline Palatine bone & 3.81 & 0.0712 & 12.72 & $<0.0001$ & 9.63 & 0.0001 \\
\hline Lingual bone & 1.2 & 0.9710 & 7.79 & 0.0002 & 6.04 & 0.0121 \\
\hline Gill arch elements & 1.21 & 0.9520 & 4.69 & 0.0321 & 5.12 & 0.0222 \\
\hline Gill rakers & 1.19 & 0.9754 & 7.73 & 0.0002 & 7.72 & 0.0002 \\
\hline Preopercle & 5.12 & 0.0345 & 12.17 & $<0.0001$ & 13.51 & $<0.0001$ \\
\hline
\end{tabular}

Development Under Altered Thyroid Status

The goitrogen treatment and administration of $\mathrm{T}_{3}$ during the larva-fry transition (from 160 to $515 \mathrm{ddph}$ ) changed the thyroid status of experimental fish (Fig. 2 and S2, in boxes). In SC and DV reared in the $0.5 \mathrm{~g}$ $\mathrm{I}^{-1}$ solution of thiourea, three-times decline of $\mathrm{T}_{4}$ content was detected. The hypothyroid SC also demonstrated a significant decrease in $\mathrm{T}_{3}$ content $\left(\mathrm{H}_{2 ; 33}=19.39 \mathrm{p}=0.0002\right)$, but the hypothyroid $\mathrm{DV}$ did $\operatorname{not}\left(\mathrm{H}_{2 ; 38}=4.36 \mathrm{p}=0.1127\right) . \mathrm{T}_{3}$ administration did not affect $\mathrm{T}_{4}$ content $\left(\mathrm{H}_{2 ; 14}=1.45 \mathrm{p}=0.4829\right)$, but significantly increased $T_{3}$ level $\left(H_{2 ; 28}=7.78 p=0.0211\right)$ in DV.

In both $\mathrm{SC}$ and DV reared under the $0.2 \mathrm{~g} \mathrm{I}^{-1}$ and $0.5 \mathrm{~g} \mathrm{I}^{-1}$ solutions of thiourea, the mortality rate was $10 \%$, and $20 \%$, respectively. The mortality rate in DV reared under $T_{3}$ treatment was higher: $25 \%$ in the $1.0 \mu \mathrm{g} \mathrm{I}^{-1}$ solution, and $55 \%$ in the $5.0 \mu \mathrm{g} \mathrm{I}^{-1}$ solution. In the control groups of DV and SC, the mortality rate was drastically lower, $1 \%$ of individuals only.

The goitrogen-caused decrease in the biochemical parameters was statistically insignificant in both groups (K-W test $p>0.50$ ), but, in fact, more pronounced in SC than in DV: $\mathrm{H}_{2 ; 58}=2.85 / \mathrm{H}_{2 ; 81}=0.37$ for the blood glucose, $=2.62 / 0.33$ for the tissue antioxidant activity, $=0.19 / 0.05$ for the phospholipid 
content, respectively. $T_{3}$ administration provoked two times stronger relative to the thiourea treating but still insignificant physiological response in DV (Fig. 3, in boxes).

The goitrogen negatively affected the fish growth rate (Fig. 1c and d). The significant differences in size were observed between normal and thiourea-treated SC (Table S3; ANOVA for length $F_{2 ; 110}=19.04 p \leq$ 0.0250). In DV, the reaction to the thiourea treatment was less pronounced; the significant size differences were revealed between the control fish and the fish reared under the $0.5 \mathrm{~g} \mathrm{I}^{-1}$ solution only $\left(F_{2 ; 143}=4.86\right.$ $p \leq 0.0011$ ). In contrast to thyroxin, $T_{3}$ administration did not affect growth rate (Fig. $1 \mathrm{c}$ and d; Table S3).

The alterations of thyroid status resulted in the developmental abnormalities. In the majority of hypothyroid SC late larvae and early fry $(90 \%)$, the body walls did not close on the belly around the remains of the yolk sac. However, we failed to find similar defects in DV late larvae and fry. The goitrogen affected development of the neural arches associated with the preural-1 vertebra. The majority of the normally developing SC (77\%) possessed the neural arches, whereas in the hypothyroid groups the frequency of their occurrence was $30 \%$ and $0 \%$ in 0.2 and $0.5 \mathrm{~g} \mathrm{I}^{-1}$ of thiourea, respectively. In the control DV, the frequency of fish with the neural arches was $27 \%$. In the hypothyroid DV reared under 0.2 and $0.5 \mathrm{~g} \mathrm{I}^{-1}$ of thiourea, it was $25 \%$ and $13 \%$, respectively. The hyperthyroid DV group differed in excessive amount of the scoliotic individuals; the frequency of this abnormality reached $40 \%$ under $1.0 \mu \mathrm{g} \mathrm{I}^{-1}$ concentration and then $90 \%$ under $5.0 \mu \mathrm{g} \mathrm{I}^{-1}$ concentration.

The changes in the skull ossification advancement in fish with altered TH status had a doze-dependent and group-specific character (Fig. 5 ac, in boxes). In the thiourea-treated SC, the postponed ossification of teeth-armed bones was observed; the relative sum ossification ranks differed significantly between three $\mathrm{SC}$ groups, i.e. control $-0.2 \mathrm{~g} \mathrm{l}^{-1}-0.5 \mathrm{~g} \mathrm{l}^{-1}$ of thiourea $\left(\mathrm{H}_{2 ; 49}=23.69 \mathrm{p}=0.0058\right)$. Within this 'module', premaxilla demonstrated the most evident developmental delay. The intraoral tongue-bite apparatus and the skull dermal bones were less affected by the thiourea $\left(\mathrm{H}_{2 ; 49}=7.12\right.$ and 6.79 respectively), only the SC reared under the $0.5 \mathrm{~g} \mathrm{I}^{-1}$ concentration differed from the control group $(p=0.0231$ and 0.0322$)$. In the hypothyroid $D V$, the dermal bones ossification displayed a significant retardation $\left(\mathrm{H}_{2 ; 66}=12.28 \mathrm{p}=\right.$ 0.0185 ) in comparison with the control group. The teeth-armed and the intraoral bones displayed similar but less pronounced reaction $\left(H_{2 ; 66}=11.28\right.$ and 9.89 respectively). A significant difference $(p \leq 0.0230)$ was detected only for the teeth-armed bones ossification ranks between the control and the $0.5 \mathrm{~g} \mathrm{I}^{-1}$ thiourea group. In the hyperthyroid DV, all bone 'modules' displayed accelerated ossification, and only the teeth-armed bones developmental advancement was significant $\left(\mathrm{H}_{2 ; 58}=9.55 \mathrm{p}=0.0301\right)$. The skull dermal bones and the intraoral bones displayed relatively weak reaction $\left(\mathrm{H}_{2 ; 58}=2.65\right.$ and 1.18 respectively). The supraethmoid ossification in the hyperthyroid DV did not exceed that in the control group.

The geometric morphometrics revealed that the hypo- and hyperthyroid DV displayed different vectors of morphological changes and were aligned along the first canonical root in $\mathrm{CV}$ morphospace in the following order: $0.5 \mathrm{gl}^{-1}$ of thiourea $-0.2 \mathrm{gl}^{-1}$ of thiourea - control $-1.0 \mu \mathrm{gl}^{-1}$ of $\mathrm{T}_{3}-5.0 \mu \mathrm{g} \mathrm{I}^{-1}$ of $\mathrm{T}_{3}$ 
(scoliotic individuals were excluded from the analysis). The vector of morphological changes in the thiourea-treated SC coincided with that in the thiourea-treated DV (Fig. 6a). The appropriate loading on landmarks (Table S1) and stretching of the 'consensus' body shape along the first root (Fig. 6b) manifested the head shortening and the anterior shift of fins in the hypothyroid fish, and precisely the opposite morphometric changes in the hyperthyroid fish. As the result of CV scaling, the hyperthyroid DV (5.0 $\mu \mathrm{g} \mathrm{I}^{-1}$ of $\left.\mathrm{T}_{3}\right)$ significantly overlapped with the control SC, whereas hypothyroid SC $\left(0.2 \mathrm{~g} \mathrm{I}^{-1}\right.$ of thiourea) overlapped with the control DV. The Procrustes distances between the groups and significance level of differences from the Procrustes ANOVA comparison are presented in Table S4.

SC demonstrated additional morphometric shift along the second canonical root (Fig. 6a). The appropriate loading on the landmarks (Table S1) and the stretching of the 'consensus' body shape along the second root (Fig. $6 \mathrm{c}$ ) displayed the reduction of the eye diameter and the maxilla length, elongation of the mandible, and the caudal shift of the ventral fins in the hypothyroid SC relative to the control one.

\section{Coniferous Infusion Impact}

The exposure of fry to the coniferous infusion resulted in the acute toxicosis and the increase of mortality. Approximately $11 \%$ (from 7 to $14 \%$ in different tanks) of DV fry died in the $1.0 \%$ solution, and 18 (323)\% of individuals died in the $1.5 \%$ solution. The SC mortality rate was $3(04) \%$ in the $1.0 \%$ solution as well as in the $1.5 \%$ solution. The $100 \%$ mortality of SC and DV fry was observed in the $3.0 \%$ solution in four days. The dead fry were characterized by typical pale anemic gills. In the control groups the mortality rate was $0 \%$.

The infusion administration induced group-specific physiological responses (Fig. 2, in boxes). It provoked a significant surge of the blood glucose level in DV $\left(\mathrm{H}_{3 ; 158}=42.33 \mathrm{p}=0.0003\right)$, but not in SC $\left(\mathrm{H}_{3 ; 115}=\right.$ $16.96 \mathrm{p}=0.0530)$. DV also demonstrated a significant increase in the tissue antioxidant activity $\left(\mathrm{H}_{2 ; 67}=\right.$ $8.38 p=0.0263)$, while $S C$ did not $\left(\mathrm{H}_{2 ; 61}=3.18 p=0.0771\right)$. The decrease in muscle phospholipid content reflecting the level of biomembrane oxi(peroxi)dation was more pronounced in $\mathrm{DV}\left(\mathrm{H}_{3 ; 97}=7.97 \mathrm{p}=\right.$ $0.0510)$ than in $\mathrm{SC}\left(\mathrm{H}_{3 ; 87}=7.21 \mathrm{p}=0.0653\right)$. In both groups, we failed to find differences (U test $\left.p>0.05\right)$ in the biochemical parameters between the control groups at the onset and at the end of the experiment.

The goitrogen and $T_{3}$ treatments altered DV response to the impact of $1.5 \%$ coniferous infusion. In the euthyroid fry, the mean mortality rate was $23 \%$ in the infusion and $0 \%$ in the pure water. In the survived euthyroid fish, an increase of $\mathrm{T}_{3}$ content $\left(+1.91 \mathrm{ng} \mathrm{g}^{-1}\right)$ was detected, but intra-sample variance remained stable. In the hyperthyroid fry, the mean mortality rate was $10 \%$ only. The survived individuals demonstrated a two-times increase of $\mathrm{T}_{3}$ content accompanied by a splash in the intra-sample variance. In the hypothyroid fry, the mean mortality rate was $54 \%$. They also manifested elevated $\mathrm{T}_{3}$ content (+ $0.34 \mathrm{ng} \mathrm{g}^{-1}$ ) and 1.5-fold drop in the variance. The alterations of $\mathrm{T}_{4}$ content were also detected (Fig. S2).

\section{Discussion}


The obtained results support the proposed scenario where spawning grounds' contamination and thyroid signaling act as drivers of the Kamchatka River S. malma diversification. We have managed to reveal the toxic influence of coniferous litter on the developing charrs and the difference in the resistance to this impact between DV and SC. The former displays a conspicuous physiological response resulting in a significant increase of the mortality. The SC reaction is less pronounced. This finding seems to address the question of different spawning sites of DV and SC. We suggest that toxic environment in the coniferous forest zone progressively built the major reproductive barrier between the morphs. SC being resistant to the adverse effects of flavonoids and terpenoids reproduce in the coniferous forest zone, while DV has to migrate upstream to the leaf krummholz zone. This situation to some extent resembles a diversification scenario of Amazonian fishes inhabiting acidic and normal water currents (Cooke et al., 2012; Pires et al., 2018).

The resistance to contamination clearly depends on the thyroid status of charrs. Under the influence of coniferous infusion, the mortality in the hyperthyroid DV was significantly lower than in the euthyroid ones. Contrariwise, in the hypothyroid fish it was significantly higher. Noteworthy, at the end of the infusion treatment the TH level in the survived eu- and hypothyroid fish was higher than at the onset. Thus, enhanced thyroid function should be considered as a reaction increasing resistance to the toxicants. However, the stress-induced intensification of the TH synthesis and enzymatic activity did not provide DV with sufficient protection against degradation of phospholipids, that manifested itself in their reducing concentration as a result of oxi(peroxi)dation (Gennis, 1989).

The physiological resistance through accelerating metabolism is a common adaptation for fishes inhabiting toxic environment (Heath, 1995; Kooijman et al., 2009; Esin et al., 2018b). Given that regulation of metabolic rate is one of the main actions of TH in fish (Janz, 2000; Blanton \& Specker, 2007; Little et al., 2013; Kitano et al., 2010, among others), the enhanced resistance in the experimental charrs apparently is of the same nature. The hyperthyroid fish displaying high resistance demonstrated the high level of metabolic rate. Contrariwise, the hypothyroid fish were characterized by low resistance and decreased metabolism. As it was described in fish dwelling in the dioxin-polluted water bodies, the hyperthyroidism may also promote a toxic resistance via the aryl hydrocarbon receptor (AhR) pathway (Hahn et al., 2004; Reitzel et al., 2014; Occhi et al., 2015). Therefore, intensification of the thyroid signaling activity seems an essential adaptation at sites within the coniferous forest zone.

The accelerated thyroid activity observed in nature and in the experiment inherent to SC in comparison with DV supported well the last proposition. Moreover, the experimental data (rearing SC and DV in the pure water) clearly indicate that $T_{3}$ content difference between morphs is not a consequence of phenotypic plasticity in response to toxic impact only, but genetically determined hormonal phenotypes: ancestral DV and hyperthyroid SC.

As it was mentioned above, TH regulate charrs' metabolic rate. The comparison of the biochemical parameters revealed that $\mathrm{SC}$ is characterized by a higher metabolic rate, both under natural and 
experimental conditions. Thus, unlike DV, SC has a physiological adaptation to the water containing excessive amount of coniferous decomposition products.

However, TH display a pleiotropic effect on the developing fish influencing a diverse range of ontogenetic events and processes (Janz, 2000; Blanton \& Specker, 2007; Shkil et al., 2012; McMenamin et al., 2014; Campinho, 2019; Eales, 2019; Keer et al., 2019; Saunders et al., 2019). It has recently been noted that developmental diversification and adaptive evolution in fishes can be promoted by differences in the thyroid axis activity (Blanton \& Specker, 2007; Kitano et al., 2010; Lema \& Kitano, 2013; Shkil et al., 2015). Apparently, a higher maternal $\mathrm{T}_{3}$ content known to have a strong impact on the subsequent developmental time scale (Mousseau \& Fox, 1998; Beck et al., 2018) led to the accelerated embryogenesis, precocious life stage transition and increased somatic growth in SC relative to DV. These developmental alterations result in the reduction of SC vertebrae count and size of otolith primordia (Melnik et al., 2020), the well-known outcome of accelerated development in fishes (Hubbs, 1922; McDowall, 2008; Pichugin et al., 2006; Esin, 2015).

SC also demonstrates the heterochronic shifts in the skull development, accelerated ossification of jaws starting from the larva-fry transition, and retarded ossification of the neurocranium. Such asynchronous craniogeny is common for charrs and is regarded as a basis for their outstanding evolutionary plasticity (Balon, 1980; Pichugin \& Chebatareva, 2011; Esin et al., 2018a). The uneven ossification of skull bones provides the possibility for some functional transformations that could promote food specialization (Parsons et al., 2011; Shkil \& Smirnov, 2015; Pabic et al., 2016). In nature SC juveniles mainly swallow large insect imagoes switching to Oncorhynchus spp. larvae consumption from the second year of life $(F L \geq 8 \mathrm{~cm})$. In contrast, DV fry and parrs prey on small-sized chironomid larvae and pupae until leaving the spawning streams (Melnik et al., 2020).

The divergence of SC - DV ontogenetic trajectories during the larva-fry transition results in obvious morphological disparities between morphs. SC acquires the advanced morphology: the elongated head with a big mouth, the robust body and the caudally shifted fins. These traits along with the increased somatic growth are commonly considered as the features typical of piscivorous fishes (Juanes et al., 2002; Alekseyev et al., 2014; Burress, 2015) and mimic the exterior shift described for Salvelinus alpinus during its transformation from the 'normal' benthivorous morph to the cannibalistic one (Alekseyev et al., 2009; Berg et al., 2010). The metabolic shift observed in SC is also characteristic of piscivorous morphs of S. malma, since it was revealed in a fish-feeding morph from the Lake Kronotskoe (Esin et al., 2018a). Moreover, a lower $\mathrm{T}_{4}$ level detected in $\mathrm{SC}$ is also inherent in the piscivorous fish possessing the highly effective thyroid metabolism (Eales, 2019). Thus, in comparison with DV, SC is characterized by multiple phenotypic peculiarities generally regarded as the features typical of piscivorous fishes (Juanes et al., 2002; Alekseyev et al., 2014; Burress, 2015; Eales, 2019), which, in case of SC, seem to be the consequences of changes in the thyroid signaling activity.

The evident morphological differences between the morphs emerge during the larva-fry transition, i.e. simultaneously with the hormonal discrepancies. This finding indicates that TH initiates the 
morphological divergence between SC and DV. It also backs up the hypothesis that the main mechanism driving sympatric microevolution in fish is an early ontogeny tuning promoting the phenotype divergence (Carroll, 2008; Wray, 2013; Abouheif et al., 2014; Brawand et al., 2014).

The artificial alterations of thyroid status provide additional evidence for the pivotal role of thyroid axis in morphological disparities between the morphs. The goitrogen treatment of SC allowed us to mimic to a certain extent an ancestral hormonal phenotype inherent in DV, and vice versa, hormonal treatment of DV - to derive a hyperthyroid phenotype typical of SC. These manipulations resulted in the morphological outcomes. The hypothyroid SC do not acquire the elongated head and caudally shifted fins typical of normal SC fry, and become morphologically closer to the control group of DV than to the control group of SC. Conversely, the hyperthyroid DV develops the advanced ossification at the expense of somatic growth and finally acquires exterior mimicking the SC morphology. Thus, we established a crucial role of thyroid axis in the development of morphological traits characteristic of SC.

Noteworthy, the dark-marble coloration typical of SC closely resembles the coloration of the marble trout belonging to Salmo trutta complex. Such SC pigmentation does not seem to be a simple reaction to the dark water and bottom, as DV always have silvery flanks at the same stream spots. In trout, the development of the pigment pattern is determined by the Wnt gene cascade (Sivka et al., 2013), whose activity is under control of the thyroid axis (Silva et al., 2017; Skah et al., 2017). This fact combined with our experimental and field data allows us to propose that thyroid axis contributes to the pigment pattern diversification of S. malma morphs since they reach the parr life stage (Fig. S1).

\section{Conclusion}

Finally, we propose the following scenario of the Kamchatka River S. malma sympatric divergence. During the Pleistocene, when spruce forests began to occupy the broad areas of the Kamchatka River basin (Barr \& Solomina, 2015; Klimaschewski et al., 2015), S. malma - a species with an amazing level of developmental plasticity - underwent the pressure of conifer litter influence. The individuals characterized by the enhanced thyroid axis activity happened to obtain an advantageous position due to an enhanced resistance to the toxic environment. These fast-growing residual individuals continually recruited a new charr group. In some anadromous salmonids, the large juveniles normally become resident, while the smaller ones migrate to the ocean (Sloat et al., 2014). Moreover, the fast-growing S. malma juveniles could acquire some head/jaw morphology serving to efficiently catch larger prey. The isolation between the newly formed resident group and anadromous fish resulted in the accumulation of genetic and phenotypic discrepancies and finally, a distinct highly specialized morph - stone charr emerged. The subsequent climate warming and coniferous forests' retreat have led to a wider distribution of the non-specialized Kamchatkan DV, which found the suitable spawning sites upstream of the coniferous zone.

Thus, S. malma represents a remarkable example of how thyroid signaling can control a diverse range of outcomes, various adaptive phenotypic novelties and riverine sympatric divergence. Our results along 
with the data concerning TH involvement in the diversification of various fish groups (Kitano et al., 2010; Lema, 2014; Shkil et al., 2015; Bolotovskiy \& Levin, 2015; Bolotovskiy et al., 2018; Prazdnikov \& Shkil, 2019; Galindo et al., 2019) indicate that thyroid axis is a prime director orchestrating the subtle phenotypic plasticity in fish promoting evolutionary diversification under shifting environmental conditions. Given that thyroid axis is a primary but not the sole endocrine factor mediating developmental alterations in response to the environmental changes, we believe that further investigations of hormonal signaling in evolutionary and ecological contexts will undoubtedly expand our understanding of the evolutionary process in fish and other taxa.

\section{Methods}

Field material collection

Mature resident SC and anadromous DV were sampled in the second-order tributaries of the Kamchatka River middle course in September 2017. The spawning grounds of SC are located in a small piedmont brook in the spruce-larch forest zone downstream of the bottomland bogs. This is a "relic" spruce-larch zone preserved only in the Kamchatka River middle course throughout the peninsula and adjacent continent regions (Dirksen et al., 2013; Klimaschewski et al., 2015). DV reproduces in the headwaters of most tributaries (including the SC spawning brook); the spawners were sampled in the mountain stream with the alder riverside forest (see Supplementary Methods section, Fig. S3). The fingerlings (characterized by the absence of an annual ring on sagittal otoliths) of both SC and DV were collected at the spawning site of SC. No individuals of intermediate phenotype were observed. The sampling site was characterized by the accumulation of the conifers' phenolic metabolites in the sediments (Melnik et al., 2020). The concentration of dry residues in the water was $2025 \mathrm{mg} \mathrm{l}^{-1}$, while only $810 \mathrm{mg} \mathrm{I}^{-1}$ at the DV spawning site (for more detailed description of the sites conditions see Table S5).

The fertilized eggs of SC and DV were obtained via the dry method. The crossing of each group was obtained by mixing the sexual products collected from three females and three males to obtain no less than 1000 viable larvae. The rate of fertilization was close to $90 \%$ in both SC and DV. The spawners from both groups were selected to be the same size $F L=4146 \mathrm{~cm}$. In two days $(48 \mathrm{~h})$, the eggs of each group were delivered to the laboratory.

Temporal characteristics of development

To compare the temporal developmental characteristics of the SC and DV ontogeny we used a traditional day*degree scale (= accumulated daily temperature). For the convenience, we divided the ontogeny in two periods: pre hatching and post hatching. Therefore, we used day*degree post fertilization to compare the timing of hatching and day*degree post hatching (ddph) to compare the timing of further development. Six postnatal developmental stages typical of salmonids, i.e. free embryo, prelarva, larva, late larva, fry and parr were identified following Balon (1985) (see Fig. S1). 
The experimental rearing lasting for 36 weeks (715 ddph) was finished at the stage of the late fry. In accordance with the data of temperature loggers installed for a year at the SC spawning site (see Melnik et al. (2020)), the age of the wild parrs was about $850 \mathrm{ddph}$. The annual dynamic of temperatures in nature is presented in Fig. S4.

\section{Experimental design}

The fertilized eggs were incubated in $250-I$ tanks filled with UV-treated soft water $(150 \mathrm{ppm}, \mathrm{pH}=7.8$, oxygen $\geq 11 \mathrm{mg} \mathrm{l}^{-1}$ ) with filtration intensity $900 \mathrm{I} \mathrm{h}^{-1}$. The newly hatched free embryos were transferred into mesh cages with the stocking density of 100 individuals per $0.004 \mathrm{~m}^{3}$ cage $\left(25000 * \mathrm{~m}^{-3}\right)$. The fry were resettled with a twice-smaller density at 16 week after hatching according to Johnston (2002) recommendations. The temperature was controlled through external chillers (Hailea HC 500A) with an accuracy of $\pm 0.3^{\circ} \mathrm{C}$. The detailed dynamics of water temperature is presented in Fig. S4. The fertilized eggs, embryos and prelarvae were reared in the dark. On the 22nd week, simultaneously with the onset of foraging, the lighting regime was changed to $10 \mathrm{~h}$ day: $14 \mathrm{~h}$ night. Hagen Sun-Glo lamps (Hagen Inc.) were used for lighting. We fed fish two times per week with the granules of Skretting Nutra feed (Nutreco N.V.). Initially the $0.3 \mathrm{~mm}$ granules were offered. Subsequently, the size of granules was gradually increased to $0.6,1.1$ and $1.5 \mathrm{~mm}$.

To study the normal development, the role of TH in ontogeny, and acute oxidative effects of coniferous substances we used three experimental sets. First, a common-garden experiment focused on the development of control groups of SC and DV from the free embryo to late fry stage. The fish were reared in cages in a single tank and sampled for the analysis six times (Table S6). As a criterion of sampling timing, we used the transition of $50 \%$ of fish from one stage to another. The specimens were collected randomly. The experimental fry were compared with the parrs collected from the nature.

The second experimental set was aimed to assess the TH involvement in SC and DV development. For this purpose, we reared the fish since $50 \%$ switching to external feeding for ten weeks (350 dd) under the hypo- and hyperthyroid conditions. In the first case we affected the SC and DV thyroid gland with the administration of goitrogen (Brown, 1997; Levin, 2010; Shkil et al., 2012; McMenamin et al., 2017; Bolotovskiy et al., 2018). Along with the goitrogen, we used thiourea (cas 62-56-6, Solins Chem.) dissolved in the aquarium water ( 0.2 and $0.5 \mathrm{~g} \mathrm{I}^{-1}$ solution). In the second case we added triiodo-Lthyronine (cas 6893-02-3, Sigma Aldrich) in the aquarium water (1.0 and $5.0 \mu \mathrm{g} \mathrm{I}^{-1}$ solution) with additional iopanoic acid (cas 96-83-3, Sigma Aldrich) treatment to inhibit deiodinases activity ( $2 \mu \mathrm{g}$ of acid to $1 \mathrm{~g}$ of fish) of DV. The experimental larvae were kept in adjacent cages in two 120 I tanks and sampled simultaneously with the control groups. Except for the thyroid function alteration, other conditions were similar to the control groups.

In the third experiment to examine the acute oxidative effects of coniferous litter decomposition products and the role of TH in the resistance to the toxic impact, we kept SC and DV fry for five days ( $30 \mathrm{dd})$ in the conifer needle infusion. To prepare the infusion, we warmed fir and larch needles up to $60{ }^{\circ} \mathrm{C}$ in soft 
water $(150 \mathrm{ppm})$ in proportion $1: 1$ with further desilting for two weeks. The working concentrations in terms of dry weight were determined based on the preliminary 96-hour test on mature Daphnia magna in $1.5,2.5$ and $3.5 \%$ of the infusion. The mean mortality in three repetition tests was 33,41 and $100 \%$, respectively.

Initially, experimental SC and DV fry were kept in the following regimes: 0.0 (control), 1.0, 1.5 and 3.0\% solutions. The toxicological experiment was performed in three repetitions using 27 I tanks with filtration intensity of $120 \mathrm{I} \mathrm{h}^{-1}$ without the UV-treatment. The physiological state (see the procedure below) and the mortality rate were assessed in fish kept under different regimes. Then, to test the role of TH in the resistance to the conifer litter decomposition products, we artificially changed the hormonal status of DV, induced hypo- $\left(0.2 \mathrm{~g} \mathrm{I}^{-1}\right.$ solution of thiourea) and hyper- $\left(1.0 \mu \mathrm{g} \mathrm{I}^{-1}\right.$ solution of triiodo-thyronine) thyroidism. After a week of the goitrogen and hormonal treatment, both groups were transferred into $1.5 \%$ infusion. The mortality rate and TH content (see the procedure below) were assessed in the hypo- and hyper thyroid groups against the DV with a normal hormonal status: fish kept in pure water and fish kept in $1.5 \%$ infusion. The duration of the experiment and all other conditions were similar to the first toxicological experiment.

\section{Data processing}

\section{Morphometrics}

The left side of every individual was photographed in the orthogonal projection with the camera DTX90 (Levenhuk). To avoid any optical distortions the image width was always at least twice the fish length, and the same zoom was applied to all images. Fork length (FL) was measured using tpsUtil and tpsDig2 v2.16 software (Rohlf, 2010). The total dry weight (W) was assessed with an accuracy of $\pm 0.001 \mathrm{~g}$. The size-weight characteristics were compared using a t-test and one-way ANOVA (Tukey test) in Statsoft v.10.0; the significance was considered at the $p<0.05$ level.

Thirteen landmarks obtained from digital images were used for the description of the head and body shape in the experimental larvae, fry and wild parrs (Fig. S5). The geometric morphometrics technique was applied for the analysis in MorphoJ v1.06d. We used the generalized Procrustes superimposition (Dryden \& Mardia, 1998) to minimize the distances between individual landmark configurations (Zelditch et al., 2004). The total variation in body shape between the groups was assessed using Procrustes ANOVA. To visualize the shape differences we used the canonical variate analysis (CVA) given a 'consensus' body shape in the sample. The loadings of the landmarks on the canonical root were estimated to evaluate their contribution to the general discrimination of the groups.

To examine the age-dependent morphometric changes we extracted the set of truss distances connecting all landmarks using tpsDig2 v2.16. The matrix of the log-transformed distances was analyzed using the Principle Components method (PCA) in Statsoft v.10.0. In this version of the analysis, the first component reflects size variation, while the second one describes the main part of body shape variability, so the 
space of the first two components displays the "channels" representing allometric relationships among fish of different size (Tissot, 1988; Mina, 2001).

Thyroid hormone content

The total triiodothyronine $\left(T_{3}\right)$ and thyroxine $\left(T_{4}\right)$ concentrations in the extract of a whole fish were evaluated by enzyme-linked immunosorbent assay (ELISA). A Barbital-free procedure adapted from Schnitzler et al. (2008) was applied. The pairs of the same-sized individuals were minced with scissors and homogenized jointly on ice for $1.5 \mathrm{~min}$ at $50000 \mathrm{rpm}$ in $4 \mathrm{ml} 96 \%$ ethanol containing $1 \mathrm{mmol}$ propylthiouracil (cas 51-52-5, Merch). In $15 \mathrm{~min}$, the mixture was centrifuged ( $2900 \mathrm{~g}, 5 \mathrm{~min}$ ) at room temperature, and the supernatant was collected. The precipitate was resuspended (3000 vortex rpm for $1 \mathrm{~min}$ ) and washed twice with $2 \mathrm{ml}$ of the working solution followed by centrifugation. The pooled supernatant was dried and coated again with $4 \mathrm{ml}$ phosphate buffer (PBS, $\mathrm{pH}=7.4$ ) (Sigma). The hormone content was measured using commercially available kits (Monobind Inc.) with a sensitivity of $0.04 \mathrm{pg} \mathrm{ml}^{-1}$ (tT3) and $3.2 \mathrm{pg} \mathrm{ml}^{-1}$ (T4). In accordance with the manufacturer's protocol, the optical density in each sample was measured in duplicate, and the mean value of the optical density was compared to the standard curve to assess the actual hormone concentration. The hormone value was recalculated to the sample weigh with the outlier values excluded. The obtained results were statistically tested by a non-parametric Kruskal-Wallis H-test and Mann-Whitney U-test in Statsoft v.10.0.

Ossification pattern

Fish were fixed with a $4 \%$ neutralized formaldehyde solution, and then stained with $0.5 \%$ Alizarin Red S (Sigma). Soft tissues were bleached and cleared with 2-5\% hydrogen dioxide in weakly alkaline medium, and then deposited in glycerol (Pichugin, 2015). We analyzed three groups of skeletal elements with clearly distinct stages of ossification: i) bones of the neurocranium supraethmoid, frontal bone, parasphenoid and series of orbital bones; ii) dermal teeth-armed bones premaxilla, maxilla, dentary, and vomer; and iii) primary tongue-bite apparatus alveolar teeth formulae on palatine and lingual bones, the number of ossified sections and rakers of the first gill arch. Additionally, we studied the development of preopercle bone.

We ranked each skeletal element according to its ossification stages (Fig. S6) and calculated the relative rank (Weisbecker et al., 2008; Koyabu et al., 2011; Esin et al., 2018a). To compare the degree and rate of skull ossification between SC and DV, we used the sums of relative ranks for neurocranium bones, teetharmed bones and tongue-bite apparatus. The effects of the size, the group (SC or DV) and their interaction on each skeletal element's ossification were evaluated using MANCOVA (Wilks' test). If a significant group effect or a size $\star$ group effect was detected, the groups were compared with U-test.

Biochemical parameters

To evaluate the overall metabolic rate and the oxidative stress status of fish we measured blood glucose, muscle phospholipid content and total antioxidant activity of tissues (Esin et al., 2018b). Following 
Harrison et al. (2011), the glucose concentration in blood obtained from the caudal vessel was measured using an automatic glucose-meter Contour TS (Bayer). The content of phospholipids was determined from the left lateral body muscle peeled from the skin and blood $(0.08 \pm 0.01 \mathrm{~g})$. The lipids were extracted following Folch et al. (1957) and purified with $0.9 \% \mathrm{NaCl}$ after shredding the tissue with scissors. The phospholipid value was obtained from enzymatic hydrolysis reaction (Takeyama et al., 1977) using a commercially available kit (Spinreact). The optical density of indicator substance kinonimin was measured at $505 \mathrm{~nm}$ wavelength against a standard solution. The remaining part of the fish was rinsed with $0.9 \% \mathrm{NaCl}$, minced with scissors and homogenized (50000 rpm for $1.5 \mathrm{~min}$ ) in $2 \mathrm{ml} 100 \mathrm{mmol}$ phosphate buffer (PBS, $\mathrm{pH}=7.4$ ) (Sigma). The total antioxidant activity of tissues was studied according to Koroluk et al. (1988). The emulsion of $1 \mathrm{ml}$ volume was added in $4 \mathrm{ml}$ of $0.01 \%$ peroxide; the reaction was stopped after $10 \mathrm{~min}$ by adding $2 \mathrm{ml}$ of $2 \%$ ammonium molybdate (cas 13106-76-8, Reachim). The concentration of peroxymolybdates was determined at the wavelength of $410 \mathrm{~nm}$ after the coagulant was separated by centrifugation ( $2900 \mathrm{~g}$ for $3 \mathrm{~min}$ ). The calculations were based on the molar extinction coefficient $\varepsilon=2220 \mathrm{I} \mathrm{mol}^{-1} \mathrm{~cm}^{-1}$ (Goth, 1991). Both $\mathrm{H}$ and $\mathrm{U}$ tests were applied to investigate the differences in characteristics among the groups.

\section{Abbreviations}

DV - Dolly Varden

$\mathrm{SC}$ - 'Stone charr'

$\mathrm{TH}$ - thyroid hormone

ddph - day*degree post hatching

$\mathrm{FL}$ - fork length

W - weight

$\mathrm{T}_{3}$ - triiodothyronine

$\mathrm{T}_{4}$ - thyroxin

CVA - canonical variate analysis

PCA - Principle Components method

\section{Declarations}

\section{Ethics approval and consent to participate}

Dolly Varden (Salvelinus malma) is not an endangered or protected species in the Russian Federation. Following the Federal law "On Fisheries and Conservation of Aquatic Biological Resources" №166-Ф3, the 
non-commercial fishing of Dolly Varden charr does not require any permissions. All field and experimental procedures with fish were carried out according to the guidelines and following the laws and ethics of the Russian Federation and approved by the ethics committee of the Severtsov Institute of Ecology and Evolution, Russian Academy of Sciences.

\section{Consent for publication}

The manuscript does not contain any individual person's data in any form

\section{Availability of data and materials}

All data generated or analyzed during this study are included in this published article [and its supplementary information files]

\section{Competing interests}

We declare the absence of competing interests

\section{Funding}

The transportation costs, as well as expenses for essential expendables, aquaria chemistry and equipment, chemicals for ELISA and biochemical analysis, food for larvae and juveniles spent during the field and laboratory works, were covered by the Russian science foundation Grant № 18-74-10085.

\section{Authors' contributions}

$\mathrm{EE}, \mathrm{GM}, \mathrm{NM}$ designed the study, sampled fish, performed experimental works and toxicological test. $\mathrm{EE}$, DK analyzed the skeleton development. EE performed morphological and biochemical analyses. EE, FS performed hormonal tests and wrote the draft. All authors read and approved final manuscript.

\section{Acknowledgments}

This work would have been impossible without the support of Mikhail A. Ezhkin (VNIRO) and Dmitry V. Zlenko (MSU). We thank the anonymous reviewers for their helpful comments and recommendations. The authors are grateful to Anastasia Sharapkova and Tatiana Gavrilova (Rosetta Stone MSU) for proofreading the manuscript.

\section{References}

1. Abouheif E, Fave MJ, Ibarraran-Viniegra AS, et al. Eco-evo-devo: the time has come. Adv. Exp. Med. Biol. 2014;781;107-125.

2. Alekseyev SS, Mina MV, Smirina E M, Sokolov AA. Late ontogeny growth acceleration and size form transformations in Transbaikalian Arctic charr, Salvelinus alpinus complex: evidence from fin ray cross section growth layers. Environ Biol Fishes. 2009;86;487-505. 
3. Alekseyev SS, Gordeeva NV, Matveev AN, et al. Three sympatric forms of Arctic charr Salvelinus alpinus complex (Salmoniformes, Salmonidae) from Lake Kamkanda, northern Transbaikalia. J ichthyol. 2014;54(6);384-408.

4. Arnegard ME, McIntyre PB, Harmon LJ, et al. Sexual signal evolution outpaces ecological divergence during Electric fish species radiation. Am Nat.2010;176(3); 335-356.

5. Balon EK. Early life histories of fishes: new developmental, ecological and evolutionary perspectives. Dordrecht:Dr. W. Junk Publ.; 1985.

6. Balon EK. Comparative ontogeny of chars. in Charrs, Salmonid Fishes of the genus Salvelinus. Perspectives in vertebrate science 1. Balon EK, editor. The Hague: Dr W. Junk Publ.; 1980. p. 703720.

7. Barr ID, Solomina O. Reprint of «Pleistocene and Holocene glacier fluctuations upon the Kamchatka Peninsula». Glob Planet Change. 2015;134;155-165.

8. Berg OK, Finstad AG, Olsen PH, Nilssen K. Dwarfs and cannibals in the Arctic: production of Arctic char (Salvelinus alpinus (L.) at two trophic levels. Hydrobiologia. 2010;652;337-347.

9. Blanton ML, Specker JL. The Hypothalamic-Pituitary-Thyroid (HPT) axis in fish and its role in fish development and reproduction. Rev. Toxicol. 2007;37; 97-115.

10. Bolnick DI, Fitzpatrick DM. Sympatric speciation: Models and empirical evidence. Rev. Ecol. Evol. 2007;38;459-487.

11. Bolotovskiy AA, Levin BA. Thyroid hormone divergence between two closely related but ecologically diverse cyprinid fish species (Cyprinidae). Biochem Syst Ecol. 2015;59;305-310.

12. Bolotovskiy AA, Levina MA, DeFaveri J, et al. Heterochronic development of lateral plates in the threespined stickleback induced by thyroid hormone level alterations. PLoS ONE. 2018;13(3), doi:e0194040, doi 10.1371/journal.pone.0194040.

13. Brawand $\mathrm{D}$, Wagner $\mathrm{CE}, \mathrm{Li} \mathrm{YI}$, et al. The genomic substrate for adaptive radiation in African cichlid fish. Nature. 2014;513;375e381.

14. Brown DD. The role of thyroid hormone in zebrafish and axolotl development. Nat. Acad. Sci. USA. 1997;94;13011-13016.

15. Brunner PC, Douglas MR, Osinov AS, et al. Holarctic phylogeography of Arctic charr (Salvelinus alpinus) inferred from mitochondrial DNA sequences. Evolution. 2001;55;573-586.

16. Bugaev VF, Vronskiy BB, Zavarina LO, et al. Fishes of the Kamchatka River basin. Kamchatpress, Petropavlovsk-Kamchatskiy, Russia. 2007. (in russian).

17. Burress ED. Cichlid fishes as models of ecological diversification: patterns, mechanisms, and consequences. Hydrobiologia. 2015;748(1);7-27.

18. Campinho MA. Teleost metamorphosis: The role of thyroid hormone. Endocrinol. (Lausanne). 2019;10;383.

19. Carroll SP. Evo-devo and an expanding evolutionary synthesis: a genetic theory of morphological evolution. Cell. 2008;134(1);25e36. 
20. Carroll, S. P., Hendry, A. P., Reznick, D. N. \& Fox, C. W. (2007). Evolution on ecological time-scales. Functional Ecology. 21(3), 387-393.

21. Chereshnev IA. Biogeography of Far Eastern freshwater fishes of Russia. Dal'nauka, Vladivostok, Russia. 1998. (in russian).

22. Cooke GM, Chao NL, Beheregaray LB. Natural selection in the water: freshwater invasion and adaptation by water color in the Amazonian pufferfish. Evol. Biol. 2012;25;1305-1320.

23. Dirksen V, Dirksen O, Diekmann B. Holocene vegetation dynamics and climate change in Kamchatka Peninsula, Russian Far East. Palaeobotany and Palynology.2013;190;48-65.

24. Dryden IL, Mardia KV. Statistical shape analysis 4. J. Wiley, Chichester. 1998.

25. Eales JG. The relationship between ingested thyroid hormones, thyroid homeostasis and iodine metabolism in humans and teleost fish. Comp. Endocrinol. 2019;280;62-72.

26. Eghbaliferiz S, Iranshahi M. Prooxidant activity of polyphenols, flavonoids, anthocyanins and carotenoids: Updated review of mechanisms and catalyzing metals. Phytother Res. 2016; 30(9);1379-1391.

27. Elias SA, Brigham-Grette J. Late Pleistocene glacial events in Beringia. in Encyclopedia of Quaternary Sci. Elias SA,Mock CJ, editors. Amsterdam: Elsiver; 2013. p. 191-201.

28. Elmer KR, Fan S, Gunter HM, et al. Rapid evolution and selection inferred from the transcriptomes of sympatric crater lake cichlid fishes. Ecol. 2010;19(s1);197-211.

29. Esin EV. Stream resident Dolly Varden Salvelinus malma of Kamchatka Peninsula. J. Ichthyol. 2015;55(2), 224-239.

30. Esin EV, Markevich GN, Pichugin MYu. Juvenile divergence in adaptive traits among seven sympatric fish ecomorphs arises before moving to different lacustrine habitats. Evol. Biol. 2018a;31(7);1018-1034.

31. Esin EV, Shul'gina EV, Shirokov DA, et al. Physiological adaptations in juvenile Dolly Varden Salvelinus malma (Salmonidae) dwelling in polluted rivers of Kamchatkan volcanic territories. Inland Water Biol. 2018b;11(2);203-214.

32. Feulner PGD, Kirschbaum F, Tiedemann R. Adaptive radiation in the Congo River: an ecological speciation scenario for African weakly electric fish (Teleostei; Mormyridae; Campylomormyrus). Physiol. Paris. 2008;102;340-346.

33. Fitzpatrick BM, Fordyce JA, Gavrilets S. What, If anything, is sympatric speciation? Evol. Biol. 2008;21(6);1452-59.

34. Folch J, Lees M, Sloan-Stanley GH. A simple method for the isolation and purification of total lipides from animal tissues. Biol. Chem. 1957;226;497-509.

35. Galindo D, Sweet E, DeLeon Z, et al. Thyroid hormone modulation during zebrafish development recapitulates evolved diversity in danionin jaw protrusion mechanics. Evol Dev. 2019;21(5);231-246.

36. Gennis RB. The structures and properties of membrane lipids. In Biomembranes: Molecular structure and function. Gennis RB, editor NY:Springer Science, 1989; p. 36-84. 
37. Golubtsov AS, Cherenkov SE, Tefera F. High morphological diversity of the genus Garra in the Sore River (the White Nile Basin, Ethiopia): one more cyprinid species flock? Ichthyol. 2012;52(11);817820.

38. Goth L. A simple method for determination of serum catalase activity and revision of reference range. Chimica Acta. 1991;196;143-152.

39. Graca MAS. The role of macroinvertebrates on leaf litter breakdown in streams - a review. Int Rev Hydrobiol. 2001;86;383-393.

40. Hahn ME, Karchner SI, Franks DG, Merson RR. Aryl hydrocarbon receptor polymorphisms and dioxin resistance in Atlantic killifish (Fundulus heteroclitus). Pharmacogenetics. 2004;14(2);131-143.

41. Harrison B, Leazenby C, Halldorsdottir S. Accuracy of the CONTOUR® blood glucose monitoring system. Diabetes Sci. Technol. 2011;5;1009-1013.

42. Heath AG. Water pollution and fish physiology 2nd ed. Boca Raton, Florida:CRS Press; 1995.

43. Hubbs CL. Variations in the number of vertebrae and other meristic characters of fishes correlated with the temperature of water during development. Am Nat. 1922;56;360-372.

44. Janz DM. Endocrine system. in The Laboratory Fish, Ostrander GK, editor, San Diego:Academic Press. 2000; p. 189-217.

45. Johnston G. Arctic charr aquaculture. Oxford:Wiley-Blackwell publ. 2002.

46. Jonsson B, Jonsson N. Polymorphism and speciation in Arctic charr. Fish Biol. 2001;58; 605-638.

47. Juanes F, Buckel JA, Scharf FS. Feeding ecology of piscivorous fishes. in Handbook of Fish Biology and Fisheries: Fish Biology, Hart PJB, Reynolds JD, editors, 2002; p. 267-283.

48. Kapralova KH, Jonsson ZO, Palsson A., et al. Bones in motion: ontogeny of craniofacial development in sympatric Arctic charr morphs. Dyn. 2015;244;1168-1178.

49. Keer S, Cohen $\mathrm{K}$, May $\mathrm{C}$, et al. Anatomical assessment of the adult skeleton of Zebrafish reared under different thyroid hormone profiles. Rec. (Hoboken). 2019;302(10);1754-1769.

50. Kitano J, Lema SC, Luckenbach JA, et al. Adaptive divergence in the thyroid hormone signaling pathway in the stickleback radiation. Biol. 2010;20(23);2124-2130.

51. Klimaschewski A, Barnekow L, Bennett KD, et al. Holocene environmental changes in southern Kamchatka, Far Eastern Russia, inferred from a pollen and testate amoebae peat succession record. Global Planet Change. 2015;134;142-154.

52. Kooijman SAL, Baas J, Bontje D, et al. Ecotoxicological applications of dynamic energy budget theory. Model.: Emer. Top. Ecotoxicol. 2009;2;237-259.

53. Koroluk MA, Ivanova LI, Maiorova IG, Tokareva VE. A method for determination of catalase activity, Delo. 1988;1;16-19.

54. Koyabu D, Endo H, Mitgutsch C, et al. Heterochrony and developmental modularity of cranial osteogenesis in lipotyphlan mammals. EvoDevo. 2011;2;21.

55. Kratochwil CF, Sefton MM, Meyer A. Embryonic and larval development in the Midas cichlid fish species flock (Amphilophus): A new evo-devo model for the investigation of adaptive novelties and 
species differences. BMC Dev. Biol. 2015;15;12; doi:10.1186/s12861-015-0061-1.

56. Laitung B, Pretty JL, Chauvet E, Dobson M. Response of aquatic hyphomycete communities to enhanced stream retention in areas impacted by commercial forestry. Freshwater Biol. 2002;47, 313323.

57. Lema SC, Kitano J. Hormones and phenotypic plasticity: implications for the evolution of integrated adaptive phenotypes. Zool. 2013;59;506e525.

58. Lema Hormones and phenotypic plasticity in an ecological context: Linking physiological mechanisms to evolutionary processes. Integr Comp Biol, 2014;54(5);850-863; doi:10.1093/icb/icu019.

59. Le Pabic P, Cooper WJ, Schilling TF. Developmental basis of phenotypic integration in two Lake Malawi cichlids. EvoDevo. 2016;7;3; doi:10.1186/s13227-016-0040-z.

60. Levin B, Bolotovskiy A, Levina $\mathrm{M}$, et al. Thyroid hormone divergence as primary factor of speciation: evidences from phenotype and RNA-seq. Front Mar Sci. 2015;2; doi 10.3389/conf.FMARS.2015.03.00176.

61. Levin B, Casal-Lopez M, Simonov E, et al. Adaptive radiation of barbs of the genus Labeobarbus (Cyprinidae) in the East African river. Freshwater Biol. 2019; doi: 10.1111/fwb.13364.

62. McDowall RM. Jordan's and other ecogeographical rules, and the vertebral number in fishes. $J$ Biogeogr. 2008;35(3);501-508.

63. McMenamin SK, Bain EJ, McCann AE, et al. Thyroid hormone-dependent adult pigment cell lineage and pattern in zebrafish. 2014;345(6202);1358-1361.

64. McMenamin SK, Carter C, Cooper WJ. Thyroid hormone stimulates the onset of adult feeding kinematics in zebrafish. Zebrafish. 2017;14(6);517-525.

65. McPhee MV, Noakes DLG, Allendorf FW. Developmental rate: a unifying mechanism for sympatric divergence in postglacial fishes? Curr Zool. 2012;58;21-34.

66. Melnik N, Markevich G, Taylor E, Esin E. The first evidence of sympatric divergence in riverine conditions of high latitudes - Stone charr and Dolly Varden form the Kamchatka River basin. $J$ Zoolog Syst Evol Res. 2020,58; doi: 10.1111/JZS.12367.

67. Mina MV. Morphological diversification of fish as a consequence of the divergence of ontogenetic trajectories. Russ J Dev Biol. 2001;32;397-401.

68. Mousseau TA,Fox CW.Maternal effects as adaptations. New York: Oxford University Press;

69. Nosil P. Ecological speciation. Oxford:Oxford University Press; 2012.

70. Occhi G, Barollo S, Regazzo D, et al. A constitutive active MAPK/ERK pathway due to BRAF ${ }^{\mathrm{V} 600 \mathrm{E}}$ positively regulates AHR pathway in PTC. Oncotarget. 2015;6(31);32104-32114.

71. Oleinik AG, Skurikhina LA, Brykov VIA. (). Phylogeny of charrs of the genus Salvelinus based on mitochondrial DNA data. Russ J Genet. 2015;51(1);55-68.

72. Ormerod SJ, Jones ME, Jones MC, Phillips DR. The effects of riparian forestry on invertebrate drift and brown trout in upland streams of contrasting acidity. Hydrol Earth Sys Sc. 2004;8; 578-588. 
73. Pabic PL, Cooper WJ, Schilling TF. Developmental basis of phenotypic integration in two Lake Malawi cichlids. Evo-Devo. 2016;7;3.

74. Parsons KJ, Sheets HD, Sk'ulason S, Ferguson MM. Phenotypic plasticity, heterochrony and ontogenetic repatterning during juvenile development of divergent Arctic charr (Salvelinus alpinus). Evol. Biol. 2011;24(8);1640-1652.

75. Parsons KJ, Trent Taylor A, Powder KE, Albertson RC. Wnt signaling underlies the evolution of new phenotypes and craniofacial variability in Lake Malawi cichlids. Nature communications. $2014 ; 5 ; 3629$; doi:10.1038/ncomms4629.

76. Pavlov SD, Savvaitova KA. The stone char of the Kamchatka river. ISACF Information Ser. 1991;5; 131-134.

77. Pialek L, Rican O, Casciotta J, et al. Multilocus phylogeny of Crencicichla (Teleostei: Cichlidae), with biogeography of the lacustris group: species flocks as a model for sympatric speciation in rivers. Mol. Phylogen. Evol. 2011;62; 46-61.

78. Pialek L, Burress E, Dragova K, et al. Preface: advances in cichlid research III: behavior, ecology, and evolutionary biology. Hydrobiologia. 2019;832; doi.org/10.1007/s10750-018-3733-6.

79. Pichugin MYu. Peculiarities of growth and skeletal system development of prelarvae, larvae, and fingerlings of Dolly Varden trout Salvelinus malma malma inhabiting the rivers of Western Kamchatka in regard to the temperature regime of the spawning grounds. J. Ichthyol. 2015;55(4);549-566.

80. Pichugin My, Chebotareva YuV. Patterns of development of the coldwater lacustrine-riverine form of the Drjagin charr (genus Salvelinus) from Lake Lama (the Taimyr Peninsula) during the larval period. Ichthyol. 2011;51(3);248-262.

81. Pichugin MYu, Sidorov LK, Gritsenko OF. On the brook chars of southern Kuril Islands and possible mechanism of the formation of dwarf forms of the Malma Salvelinus malma curilus. Ichthyol. 2006;46(2);162-177.

82. Pietta PG, Simonetti P, Mauri P. Antioxidant activity of selected medicinal plants. J. Agric. Food Chem. 1998;46;4487-4490.

83. Pires THS, Borghezan EA, Machado VN, et al. Testing Wallace's intuition: water type, reproductive isolation, and divergence in an Amazonian fish. Evol Biol. 2018;31(6);882-892.

84. Powder KE, Milch K, Asselin G, Albertson RC. Constraint and diversification of developmental trajectories in cichlid facial morphologies. EvoDevo. 2015;6;25; doi:10.1186/s13227-015-0020-8.

85. Prazdnikov DV, Shkil FN. Experimental evidence of the role of heterochrony in evolution of the Mesoamerican cichlids pigment patterns. Evol Dev. 2019;21;3-15.

86. Reitzel AM, Karchner SI, Franks DG, et al. Genetic variation at aryl hydrocarbon receptor (AHR) loci in populations of Atlantic killifish (Fundulus heteroclitus) inhabiting polluted and reference habitats. Biol. 2014;14;6.

87. Robinson BW, Wilson DS. Character release and displacement in fishes: a neglected literature. Nat. $1994 ; 144 ; 596-627$. 
88. Robinson BW, Parsons KJ. Changing times, spaces, and faces: tests and implications of adaptive morphological plasticity in the fishes of northern postglacial lakes. Can J Fish Aquat Sci. 2002;59(11);1819-1833.

89. Rohlf FJ. TpsDig (ver. 2.16.). Department of Ecology and Evolution, State Univ., New York. 2010.

90. Salmenkova EA, Omelchenko VT, Afanasyev KI, et al. Genetic divergence of populations of the White char Salvelinus albus, Northern and Southern forms of Malma malma (Salmonidae), by microsatellite loci of DNA. J Ichthyol. 2009;49(9);730-740.

91. Salzburger W. Understanding explosive diversification through cichlid fish genomics. Nat Rev Genet. 2018;19;705-717.

92. Saunders LM, Mishra AK, Aman AJ, et al. Thyroid hormone regulates distinct paths to maturation in pigment cell lineages. eLife. 2019;8; e45181; doi:10.7554/eLife.45181.

93. Savvaitova KA. Morphological features and variability of local populations of the Arctic charr lakeriver forms from the Kamchatka River basin. Voprosi Ichtiologii. 1970;10(2);300-318 (in russian).

94. Savvaitova KA. (1989). Arctic charrs (population systems structure, prospects of economic use). Moscow: Agropromizdat. 1989. (in russian).

95. Savvaitova KA, Maksimov VA. Stone charr from the Kamchatka River basin. Reports of the Higher School of Biological Sciences. 1970;5;7-20. (in russian).

96. Schluter D. Ecological speciation in postglacial fishes. Philosophical Trans. Royal Soc. London. Ser. B. 1996;351;807-814.

97. Schnitzler JG, Koutrakis E, Siebert U, et al. Effects of persistent organic pollutants on the thyroid function of the European sea bass (Dicentrarchus labrax) from the Aegean sea, is it an endocrine disruption? Mar Pollut Bull. 2008;56(10);1755-1764.

98. Schwarzer J, Misof B, Ifuta SN, Schliewen UK. Time and origin of cichlid colonization of the lower Congo rapids. PLoS One. 2011;6(7);e22380.

99. Shkil FN, Smirnov SV. Experimental approach to the hypotheses of heterochronic evolution in lower vertebrates. J.2015;49; 1624-1634.

100. Shkil FN, Kapitanova DV, Borisov VB, et al. Thyroid hormone in skeletal development of cyprinids: Effects and morphological consequences. J Appl Ichthyol. 2012;28;398-405.

101. Shkil FN, Lazebnyi OE, Kapitanova DV, et al. Ontogenetic mechanisms of explosive morphological divergence in the Lake Tana (Ethiopia) species flock of large African barbs (Labeobarbus; Cyprinidae; Teleostei). Russ J Dev Biol. 2015;46(5);294-306.

102. Silva N, Louro B, Trindade $M$, et al. Transcriptomics reveal an integrative role for maternal thyroid hormones during zebrafish embryogenesis. Sci Rep. 2017;7;

103. Sivka U, Snoj A, Palandačić A, Bajec Identification of candidate genes involved in marble color pattern formation in genus Salmo. Comp Biochem Physiol. Part D: Genomics and Proteomics. 2013;8(3);244-249. 
104. Skah S, Uchuya-Castillo J, Sirakov M, Plateroti M. The thyroid hormone nuclear receptors and the Wnt/ $\beta$-catenin pathway: An intriguing liaison. Dev Biol. 2017;422(2);71-82.

105. Sloat MR, Reeves GH. Individual condition, standard metabolic rate, and rearing temperature influence steelhead and rainbow trout (Oncorhynchus mykiss) life histories. J. Fish. Aquat. Sci. 2014;71(4);491-501.

106. Smith TB, Skulason S. Evolutionary significance of resource polymorphisms in fishes, amphibians, and birds. Rev. Ecol. Syst. 1996;27;111-133.

107. Sullivan JP, Lavoué S, Hopkins CD. Discovery and phylogenetic analysis of a riverine species flock of African electric fishes (Mormyridae: Teleostei). Evolution. 2002;56(3);597-616.

108. Takeyama M, Itoh S, Nagasaki T, Tanimizu I. A new enzymatic method for determination of serum choline-containing phospholipids. Chem. Acta. 1977;79;93-98.

109. Tissot BN. Multivariate analysis. in Heterochrony in evolution: A multidisciplinary approach McKinney ML, editor. New-York:Plenum Press. 1998;p.35-51.

110. Tremolieres M. Deoxygenating effect and toxicity of ground-up dried coniferous needles and deciduous leaves of canadian trees in water: A preliminary study in comparison with litter of european trees. Water Res. 1988;22(1);21-28.

111. Via C. In the Light of Evolution Vol. III. in Two Centuries of Darwin. Avise JC, Ayala FJ, editors. Washington (DC):National Academies Press. 2013.

112. Weisbecker V, Goswami A, Wroe S, Sánchez-Villagra MR. Ossification heterochrony in the therian postcranial skeleton and the marsupial-placental Evolution. 2008;62;2027-2041.

113. Wray GA. Genomics and the evolution of phenotypic traits. Rev. Ecol. Evol. Syst. 2013;44;51e72.

114. Zelditch ML, Swiderski DL, Sheets HD, Fink WL. Geometric morphometrics for biologists: A primer. New-York \& London:Elsevier Academic Press. 2004.

\section{Additional Files}

Additional file 1. Figure S1. Postembryonic development of stone charr and Dolly Varden: A free embryo (1) has an undifferentiated fin fold and no ossification in fins; its behavior is passive (lying on the flank). A prelarva (2) is characterized by the dorsal fin separated from the fin fold, and ossified rays in the dorsal and caudal fins; the behavior turns to active negative phototaxis. A larva (= alevin, 3 ) displays ossification in all fins; fish demonstrate positive phototaxis and swallow food. A late larva (4) possesses the yolk suck remnants, the separated anal fin and segmented ossified rays in all fins; fish swim freely in the water column. Fry (5) demonstrate the absence of the yolk suck and fin fold; pores of the lateral line start to ossify. A parr (= a fingerling, 6 ) acquires small bright spots specific to charrs and displays initial squamation.

Arrows indicate the parr mark used to count the melanophores (the first parr mark located on the trunk near the posterior margin of the dorsal fin). In the experimental fry the parr mark contained 109-158 melanophores (mean value 133.8 \pm 2.05$)$ in SC and 105-154 (131.0 \pm 2.13$)$ in DV [U-test df $=55 p=$ 
0.0854]. In the wild parrs, the parr mark contained 121-177 (148.7 \pm 2.16$)$ in SC against 113-166 (140.9 \pm 2.01) in DV [U test $d f=49 p=0.0376]$

Additional file 2. Figure S2. The whole-body $\mathrm{T}_{4}$ profile of SC (solid red) and DV (dashed brown) during the development. Mean and min-max values are shown; asterisks indicate significantly different (t-test $p<$ $0.01)$ pairs of samples. In boxes on the left: the parameters in the groups reared $350 \mathrm{dd}$ under different concentrations of thiourea and external $\mathrm{T}_{3}$, as well as reared $30 \mathrm{dd}$ under conifer infusion impact.

The samples of the 315- and 620-ddph SC were removed from the analysis as the results of $T_{4}$ measurement differed in abnormally high spread of values and the presence of values below the stated measurement accuracy of $3.2 \mathrm{pg} \mathrm{ml}^{-1}$

Additional file 3. Figure S3. Sites of sampling in the Shapina and Kimitina River basins, Kamchatka. The spawning grounds were selected as the most easily accessible in the basin to provide timely export of the fertilized eggs

Additional file 4. Figure S4. Temperature profiles in the experiments (blue line, daily fluctuations of temperature relative to the mean values were within $\pm 0.3^{\circ} \mathrm{C}$ ) and in nature (red-shadowed line - mean 5day temperature fluctuations at the stone charr spawning ground).

Strokes below indicate the timing when $50 \%$ of individuals reach the next developmental stage in the common-garden experiment (red for stone charr, dashed brown for Dolly Varden): 1 - fertilization, 2 hatching, 3 - prelarva, 4 - feeding larva, 5 - late larva, 6 - fry

Additional file 5. Figure 5. Landmarks used in morphometric analysis. Measurements of linear morphological traits: 1-13 = fork length, 1-12 = body length, 1-5 $=$ head length, 1-2 $=$ snout size, $2-3=$ eye diameter, $1-4=$ length of maxilla, 6-7 = head height (h1), 8-9 = body height (h2), 10-12 = caudal peduncle height (h3), 1-8, 1-9, 1-11 and 9-11 = predorsal, preventral, preanal and P-V distances, respectively

Additional file 6. Figure 6. Ossification stages of the cranial elements used for the analysis. Scores for:

- tooth-bearing bones:

premaxilla ( 0 - absence of ossification, 1 - acerate primordium, 2 - the first formed teeth, 3 - separated ascending process and osteal base with 2-3 teeth, 4 - active ossification of teeth, partially nongerminated, 5 - formed bone with $\geq 7$ teeth); maxilla $(0,1$ - acerate primordium with $\leq 5$ teeth, 2 separated anterior articular surface and $\leq 8$ teeth, 3 - separated posterior supramaxillar element and $\leq$ 10 teeth that not reach supramaxilla edge, 4 - formed bone, tooth row continues over supramaxilla edge, 5 - articular process enters premaxilla notch); dentary ( 0,1 - acerate primordium, 2 - closed apertures along the bottom margin, 3 - formed walls of seismosensory channel, 4 - channel is closed, tooth row is not complete, 5 - complete tooth row, 6 - formed posterior articular processes, superposition with the articular bone); vomer ( 0,1 - paired primordium, 2 - fused scute, 3 - separated head and arm, 4 - bone with germinal teeth, 5 - head with formed processes, 6 - full tooth row); 
- bones of neurocranium:

supraethmoid $(0,1$ - paired primordium, 2 - fused scute, 3 - scute with posterior process, 4 - scute with lateral and posterior processes, 5 - formed merged bone); frontal (0, 1 - primordium of orbital edge, 2 plate with vallecula of seismosensory channel, 3 - formed walls of channel, 4 - enlarged plate with anterior process and closed channel, 5- posterior edge covers cranial fontanel and contact opposite bone, 6 - right and left bone plates locked along the sagittal axis); parasphenoid $(0,1$ - acerate primordium, 2 - primordium with thin lateral processes, 3 - clavate lateral processes, 4 - formed posterior apertures and anterior widening, 5 - formed anterior apertures); orbital series $(0,1-$ only lacrimal bone, 2-5 - ossification of suborbital row, 6-7 - late ossification of preorbital elements [= supraorbitale-3 and supraorbitale-2]);

- quantitative elements of primary splanchnocranium:

number of alveolar teeth on palatine bone (from 1 to 8 ); lingual bone (from 2 to 11); number of ossified sections of the first gill arch (from 1 to 5 including frontal basihyal element) and number of rakers on the first gill arch (from 1 to 15). Not all alternatives of development are shown on the figure.

- preopercle (0, 1 - fused scute, 2 - superior plate with seismosensory apertures, 3 - formed walls of seismosensory channel, 4 - channel is closed, 5 - inferior process protrude over the opercle edge, crests are formed).

Position of the bones is shown additionally on the skull

\section{Additional file 7. Tables S1-S6.}

Table S1. Loadings of landmarks on the principal component axes and canonical roots in the analysis of fish body shape variability.

Table S2. Linear morphometric measurements for experimental fry and natural parrs ( $>650 \mathrm{ddph})$.

Table S3. Significance level of differences (ANOVA) for the body length (on the top) and weight (below) among the groups.

Table S4. Procrustes distances $\left({ }_{\star} 10^{-2}\right.$, on the top) and significance level of differences (below) from the Procrustes ANOVA comparison $\left(F_{75 ; 698}=7.958 \mathrm{SS}_{\text {ind/res }}=0.015 / 0.055\right)$ of the groups .

Table S5. Characteristics at the spawning grounds of stone charr and those of Dolly Varden from the Kamchatka River basin during the reproduction period.

Table S6. Experimental design and sample size (SC / DV, number of individuals used).

\section{Figures}




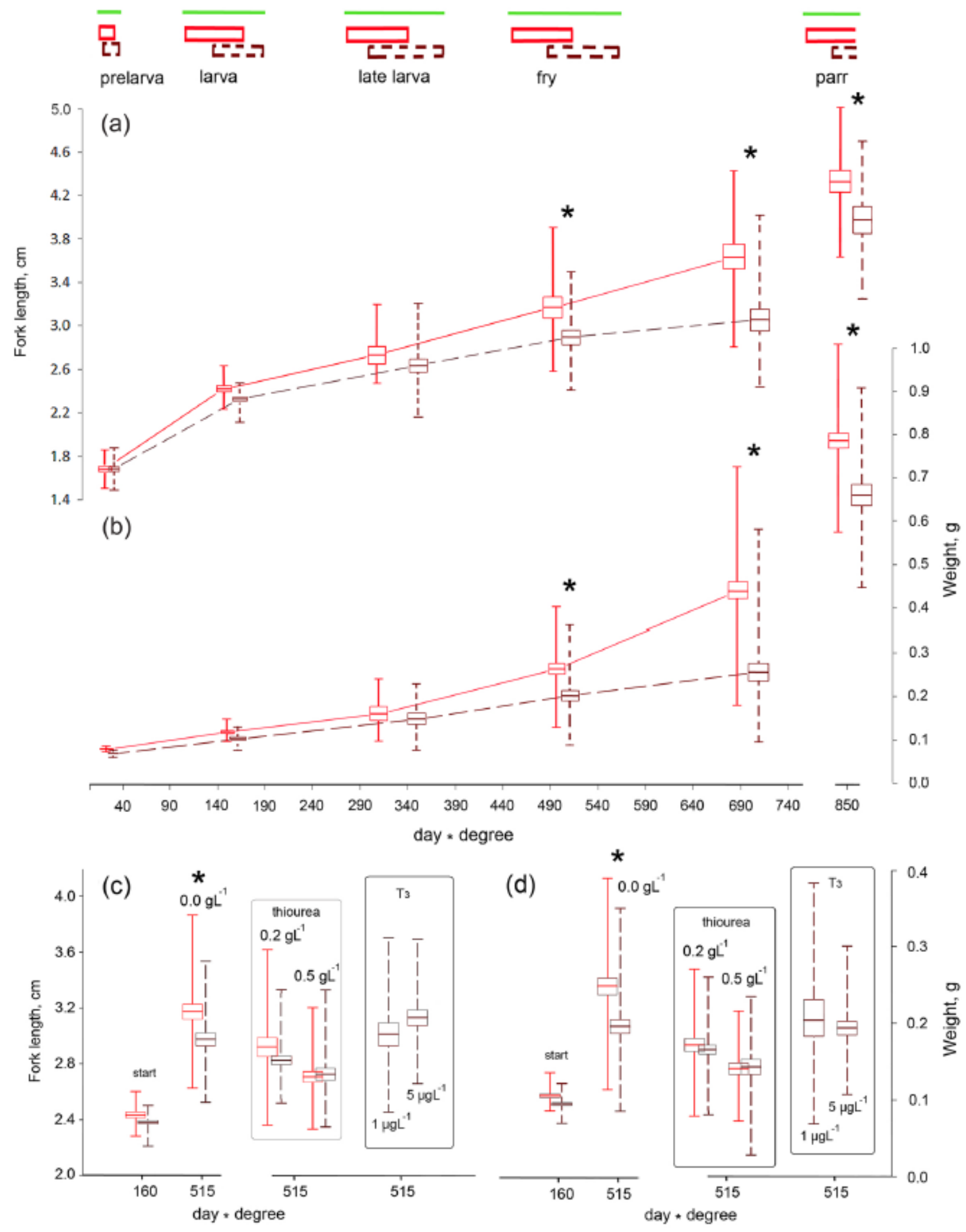

\section{Figure 1}

Postnatal somatic growth of SC (solid red) and DV (dashed brown). Mean \pm SE and min max values are shown; asterisks indicate significantly different (t-test $p<0.01$ ) pairs of samples. (a) Fork length and (b) Weight increase in the common-garden experiment. 850 ddph juveniles represent parrs in the wild. (c) Fork length and (d) Weight in the groups reared $350 \mathrm{dd}$ under different concentrations of thiourea and 
external T3 (in boxes) against the control groups. Dashes upon the graphs represent the period of transition to the next developmental stage.

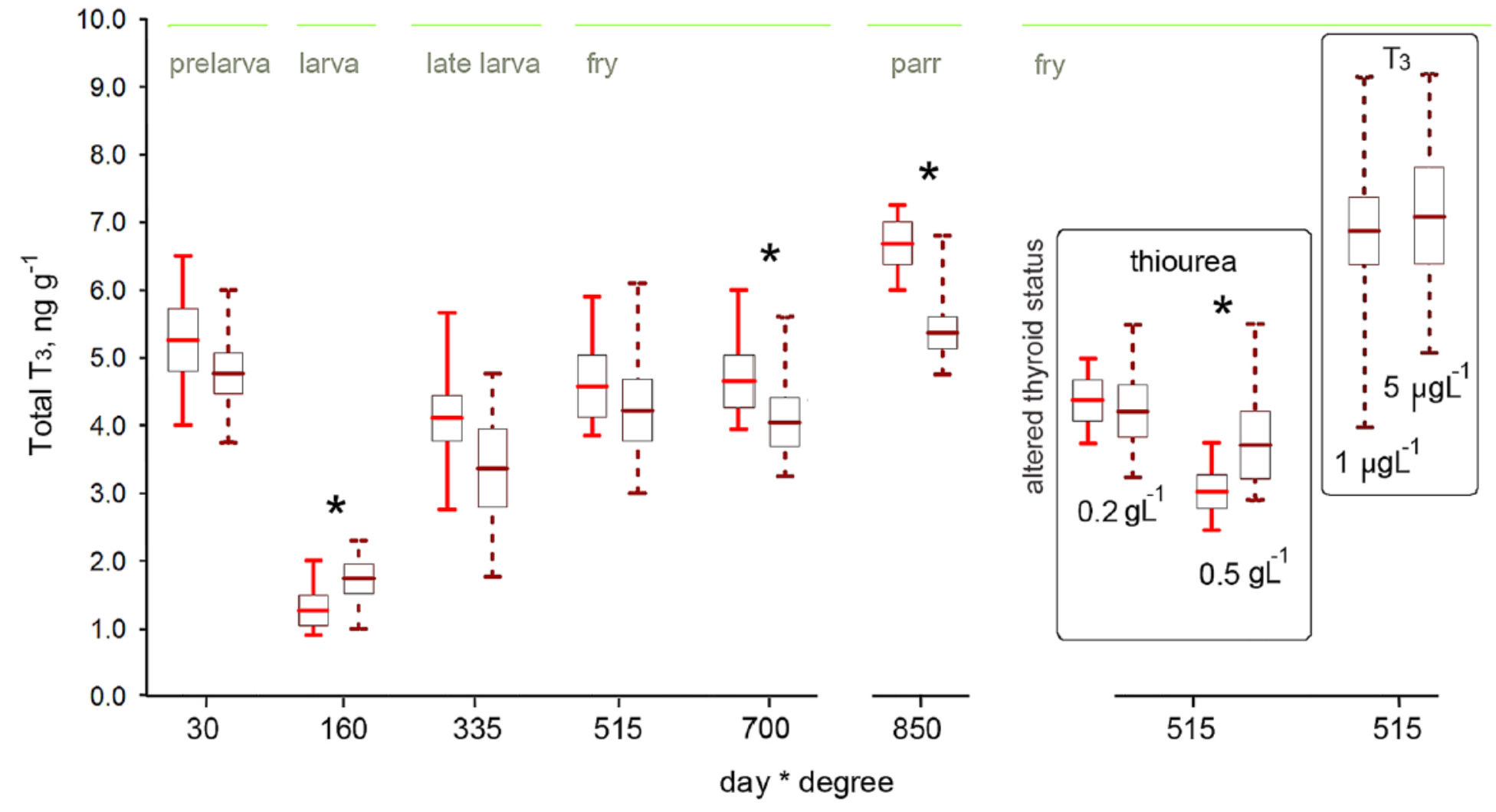

Figure 2

Whole-body T3 profiles of SC (solid red) and DV (dashed brown). Mean \pm SE and min max values are shown; asterisks indicate significantly different (U-test $p<0.05)$ pairs of samples. 850 ddph juveniles represent parrs in the wild. In boxes on the left: T3 content in the groups reared $350 \mathrm{dd}$ under different concentrations of thiourea and external T3 (the values for the T3 administration experiment are represented by deducting the external hormone concentration). 

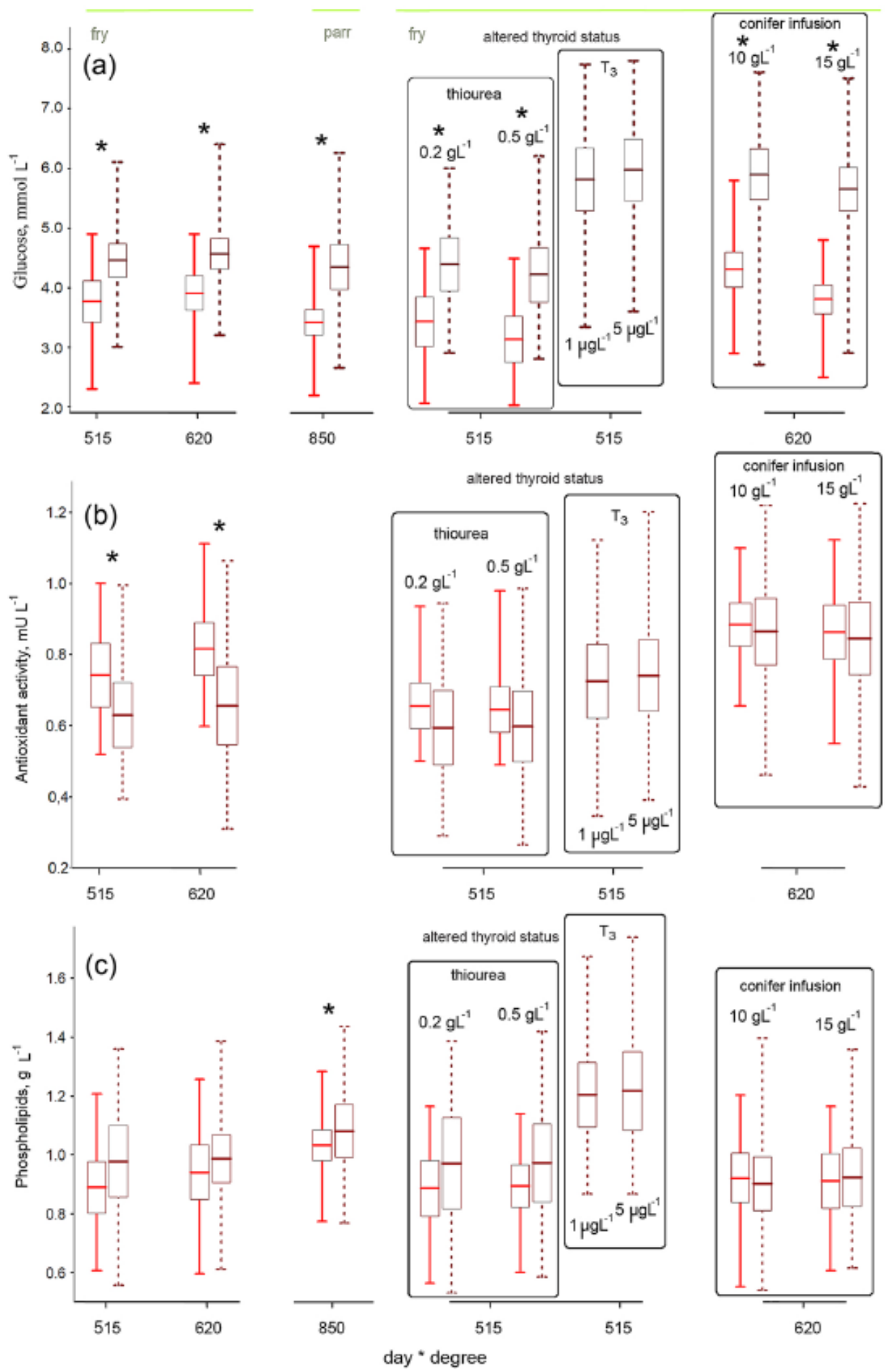

Figure 3

Biochemical parameters in SC (solid red) and DV (dashed brown). Mean \pm SE and min max values are shown; asterisks indicate significantly different (U-test $p<0.05)$ pairs of samples. (a) Blood glucose level, (b) Tissue antioxidant activity and (c) Muscle phospholipid content. 850 ddph juveniles represent parrs in the wild. In boxes on the left: the parameters in the groups reared $350 \mathrm{dd}$ under different concentrations of thiourea and external T3, as well as reared $30 \mathrm{dd}$ under different concentrations of conifer infusion 


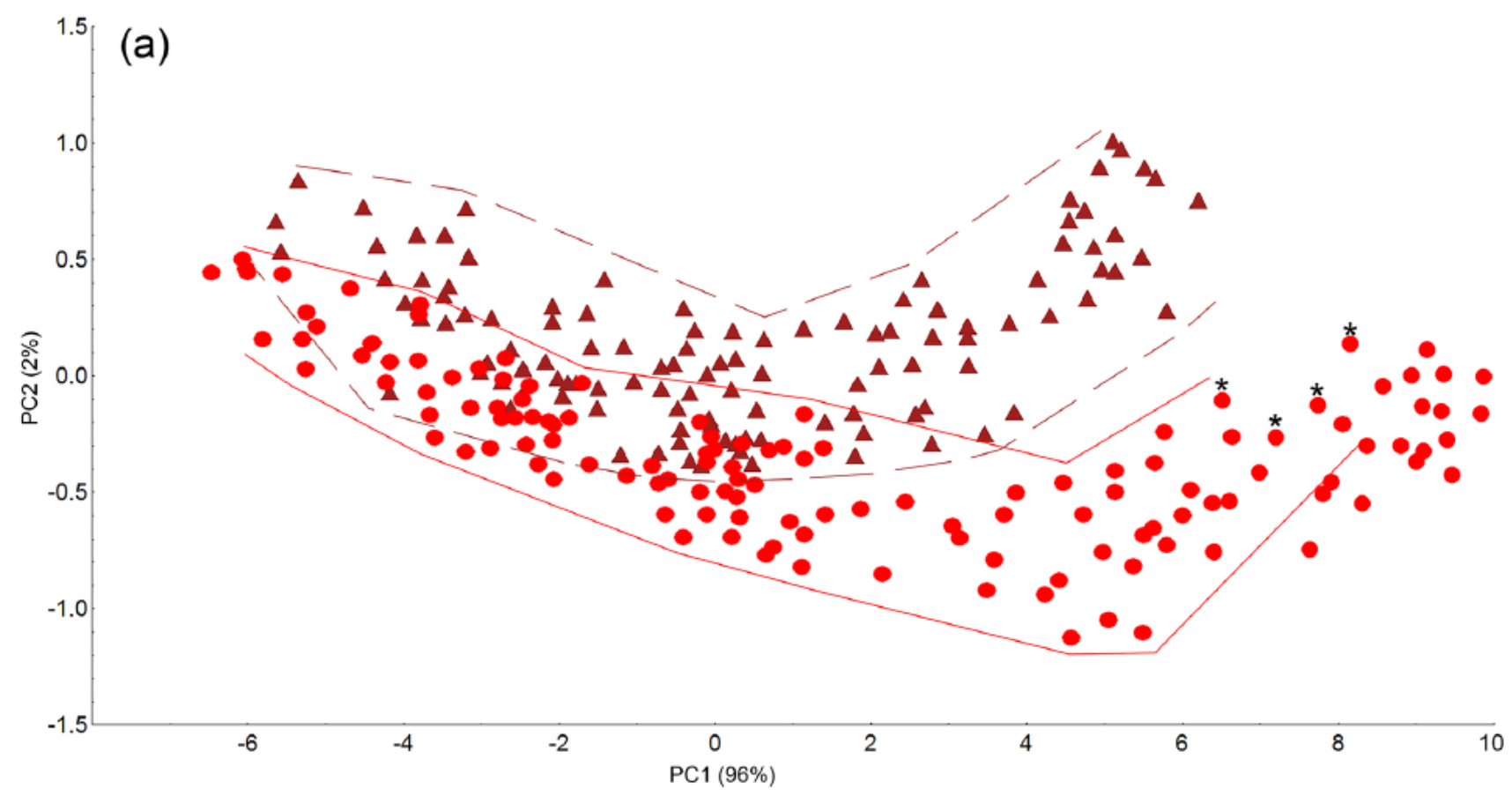

(b)

(c)
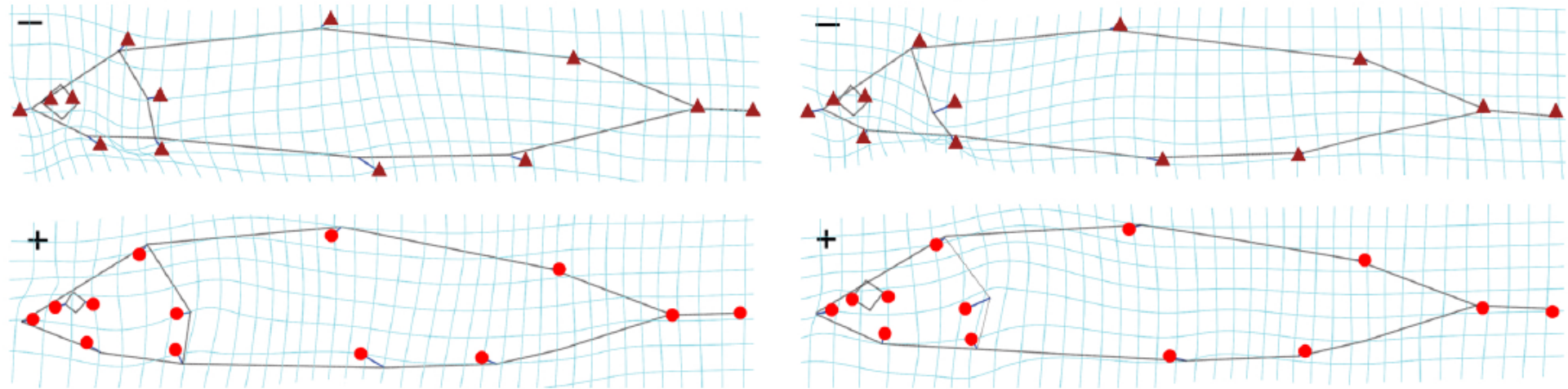

Figure 4

Developmental dynamics of morphs body shape in common-garden experiment. Principal component (PC) scores for body shape of SC (red dots) and DV (brown triangles) plotted together with growth (a). Deformation of the grid represents the change in body shape along the canonical root for older fry in the experiment (b) and for parrs in the wild (c). 

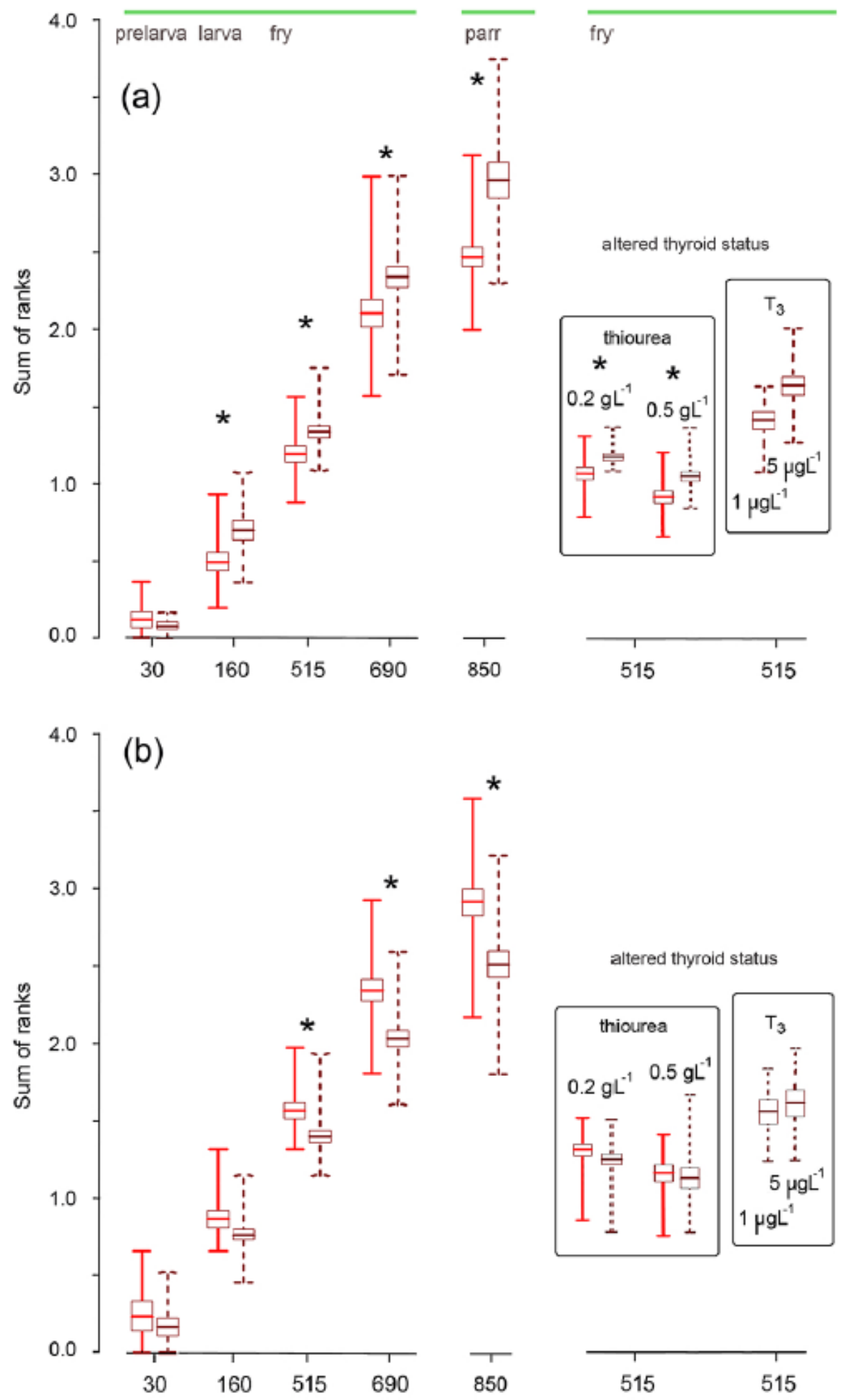

\section{Figure 5}

Ossification ranks of three skull element 'modules' in SC (solid red) and DV (dashed brown). Mean \pm SE and min max values are shown; asterisks indicate significantly (U-test $p<0.05)$ different pairs of samples. (a) Supraethmoid, frontal, orbital series and parasphenoid bones, (b) Premaxilla, maxilla, dentary and vomer, (c) Palatine, lingual bone and first gill arch with gill rakers. 850 ddph juveniles 
represents parrs in the wild. In boxes on the left: ossification ranks in the groups reared $350 \mathrm{dd}$ under different concentrations of thiourea and external T3.

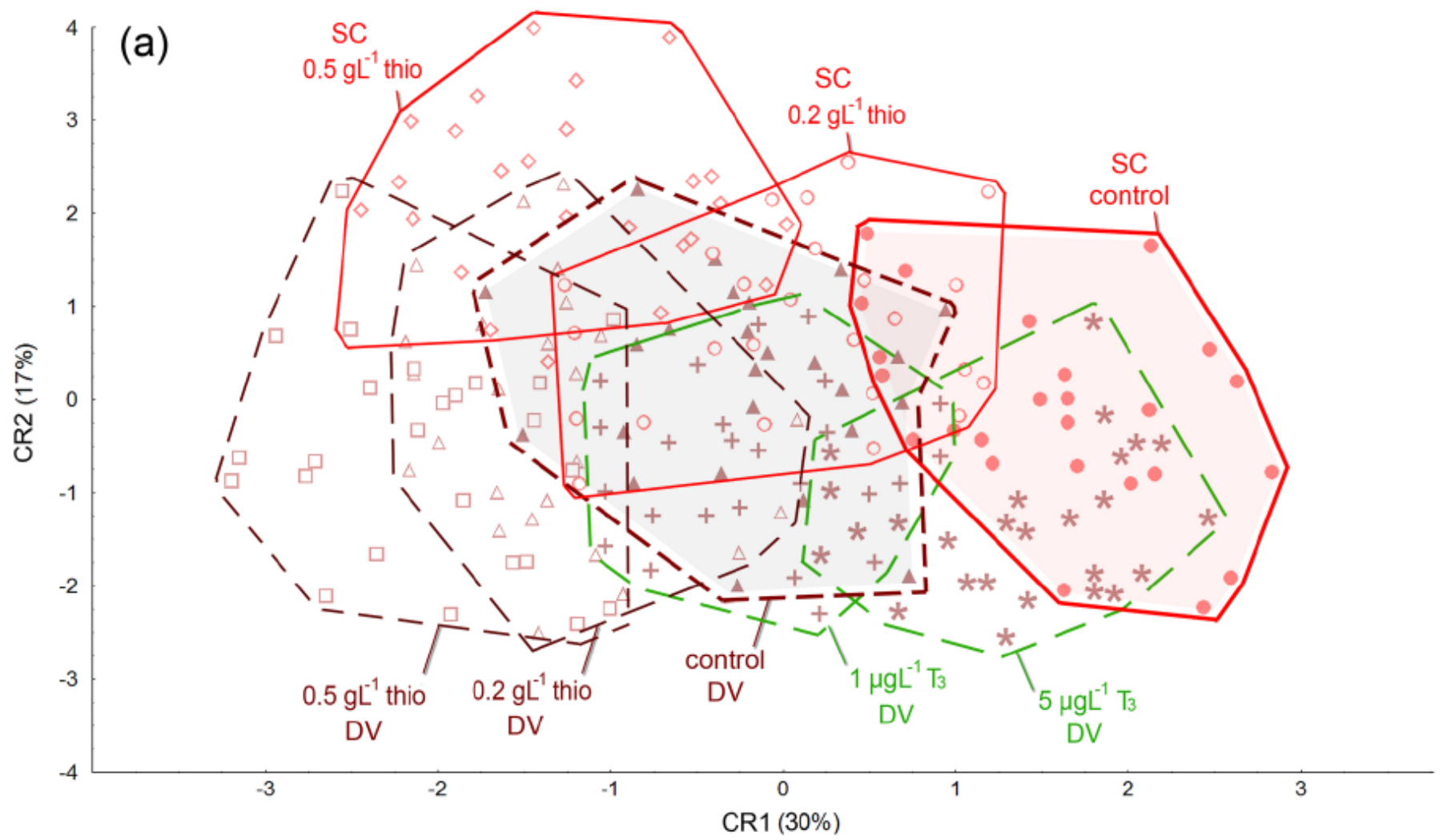

(b)
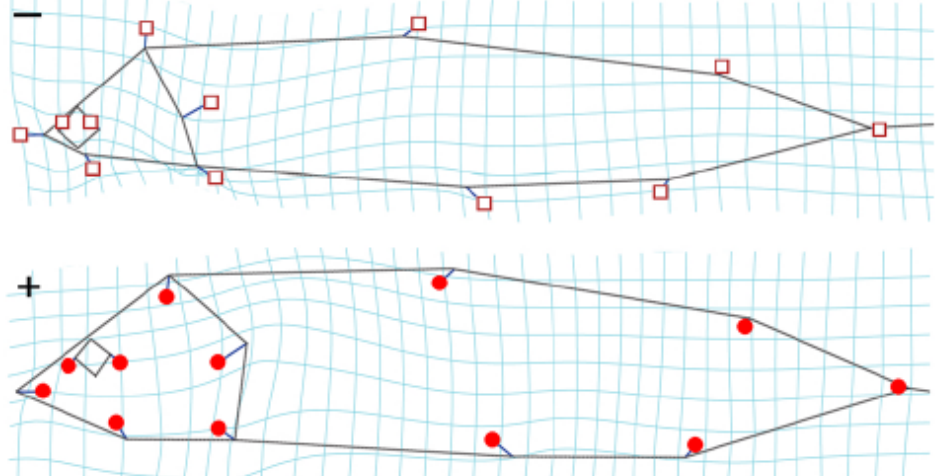

(c)
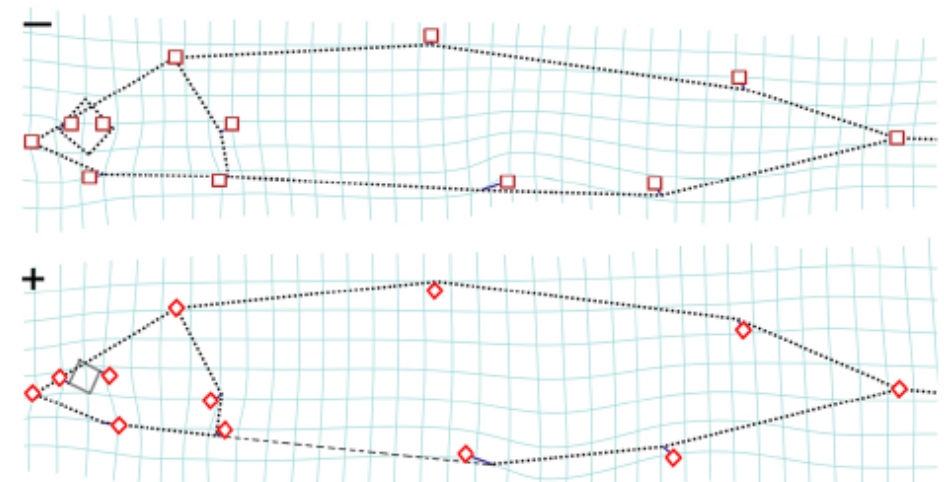

Figure 6

Body shape of morphs reared $350 \mathrm{dd}$ under different hormonal regimes. Plot of canonical scores (CR) for

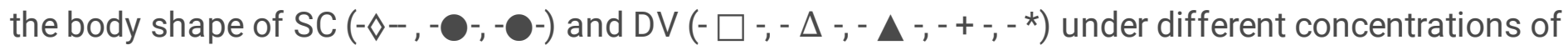
thiourea and external T3 (a, numbers indicate concentrations; the areas of control groups are filled). Deformation of the grid represents the change in body shape along the first (b) and the second (c) canonical root.

\section{Supplementary Files}


This is a list of supplementary files associated with this preprint. Click to download.

- Additionalfile7.docx

- Additionalfile6.pdf

- Additionalfile3.pdf

- Additionalfile4.pdf

- Additionalfile1.pdf

- Additionalfile5.pdf

- Additionalfile2.pdf 